\title{
Nonlinear Features of Realized FX Volatility
}

John M. Maheu, Thomas H. McCurdy

\begin{tabular}{c}
\hline Série Scientifique \\
Scientific Series
\end{tabular}

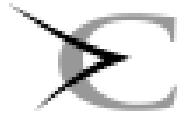




\section{CIRANO}

Le CIRANO est un organisme sans but lucratif constitué en vertu de la Loi des compagnies du Québec. Le financement de son infrastructure et de ses activités de recherche provient des cotisations de ses organisationsmembres, d'une subvention d'infrastructure du ministère de la Recherche, de la Science et de la Technologie, de même que des subventions et mandats obtenus par ses équipes de recherche.

CIRANO is a private non-profit organization incorporated under the Québec Companies Act. Its infrastructure and research activities are funded through fees paid by member organizations, an infrastructure grant from the Ministère de la Recherche, de la Science et de la Technologie, and grants and research mandates obtained by its research teams.

\section{Les organisations-partenaires / The Partner Organizations}

-École des Hautes Études Commerciales

-École Polytechnique

-Université Concordia

-Université de Montréal

-Université du Québec à Montréal

-Université Laval

-Université McGill

-Ministère des Finances du Québec

-MRST

-Alcan inc.

-AXA Canada

-Banque du Canada

-Banque Laurentienne du Canada

-Banque Nationale du Canada

-Banque Royale du Canada

-Bell Québec

-Bombardier

-Bourse de Montréal

-Développement des ressources humaines Canada (DRHC)

-Fédération des caisses populaires Desjardins de Montréal et de l'Ouest-du-Québec

-Hydro-Québec

-Industrie Canada

-Pratt \& Whitney Canada Inc.

-Raymond Chabot Grant Thornton

-Ville de Montréal

(C) 2001 John M. Maheu et Thomas H. McCurdy. Tous droits réservés. All rights reserved. Reproduction partielle permise avec citation du document source, incluant la notice $\odot$.

Short sections may be quoted without explicit permission, if full credit, including $\odot$ notice, is given to the source.

Ce document est publié dans l'intention de rendre accessibles les résultats préliminaires de la recherche effectuée au CIRANO, afin de susciter des échanges et des suggestions. Les idées et les opinions émises sont sous l'unique responsabilité des auteurs, et ne représentent pas nécessairement les positions du CIRANO ou de ses partenaires.

This paper presents preliminary research carried out at CIRANO and aims at encouraging discussion and comment. The observations and viewpoints expressed are the sole responsibility of the authors. They do not necessarily represent positions of CIRANO or its partners.

ISSN 1198-8177 


\title{
Nonlinear Features of Realized FX Volatility ${ }^{*}$
}

\author{
MaJohn M. Maheu ${ }^{\dagger}$, Thomas H. McCurdy \\ Résumé / Abstract
}

Dans cet article, nous étudions les caractéristiques nonlinéaires de la dynamique de la volatilité des taux de change à l'aide d'estimations de la volatilité quotidienne basées sur la somme du carré des rendements intraquotidiens. Les erreurs de mesure commises en utilisant la volatilité réalisée pour mesurer la volatilité latente ex post font en sorte que les modèles standards de séries chronologiques de la variance conditionnelle deviennent des variantes d'un modèle ARMAX. Nous explorons des alternatives nonlinéaires à ces spécifications linéaires en utilisant un processus doublement stochastique, avec mixage dépendant de la durée. Ce processus peut capter des changements importants et abrupts dans le niveau de la volatilité, de même qu'une persistence et une variance de la volatilité variant dans le temps. Nos résultats influent sur la précision des prévisions, la couverture et l'évaluation des produits dérivés.

This paper investigates nonlinear features of $F X$ volatility dynamics using estimates of daily volatility based on the sum of intraday squared returns. Measurement errors associated with using realized volatility to measure ex post latent volatility imply that standard time series models of the conditional variance become variants of an ARMAX model. We explore nonlinear departures from these linear specifications using a doubly stochastic process under durationdependent mixing. This process can capture large abrupt changes in the level of volatility, time varying persistence, and time-varying variance of volatility. The results have implications for forecast precision, hedging, and pricing of derivatives.

Mots Clés : Données à haute fréquence, volatilité réalisée, demi-Markov

Keywords: High-frequency data, realized volatility, semi-Markov

JEL : G150, C220

\footnotetext{
* Corresponding Author: Thomas H. McCurdy, CIRANO, 2020 University Street, $25^{\text {th }}$ floor, Montréal, Qc, Canada H3A 2 A5 Tel.: (514) 985-4000

Fax: (514) 985-4039 email: tmccurdy@mgmt.utoronto.ca We are grateful to Olsen and Associates (Zurich) for providing the intraday exchange rate quotations and to the Social Sciences and Humanities Research Council of Canada for financial support. We also thank Torben G. Andersen, Mark Cassano, Peter Christoffersen, Frank Diebold, Jin-Chuan Duan, John Galbraith, René Garcia, Nour Meddahi, Paul Michaud, Adrian Pagan, Éric Renault, Marcel Rindisbacher, Jeffrey Russell, Ilias Tsiakas, as well as participants at the Canadian Econometrics Study Group, the NBER Summer Institute 2000 (Forecasting \& Empirical methods in Macroeconomics \& Finance), the CIRANO-MITACS Finance Day (Montréal, Jan. 2000), the Financial Econometrics Conference (University of Waterloo, March 2000), and seminar participants at the University of Calgary, H.E.C., Université de Montréal, McGill University, Queen's University, and University of Victoria for helpful comments and suggestions. Two referees provided very helpful and constructive suggestions.

${ }^{\dagger}$ University of Alberta

* University of Toronto and CIRANO
} 


\section{Introduction}

Volatility is a prevailing feature of financial markets. Its presence implies both risks and opportunities. Although asset returns are often represented as a martingale difference series, volatility displays persistence and should therefore be predictable. However, the data generating process (DGP) for volatility is unobservable. Therefore most studies have used a fully specified conditional mean and conditional variance model to estimate and analyze that latent volatility. What has been learned from past studies is dependent upon the maintained statistical model and estimation procedures.

An alternative would be to use an observable proxy for latent volatility. A standard proxy for ex post daily volatility has been daily squared returns or squared residuals from a regression model for returns. However, these measures of volatility can be very noisy. ${ }^{1}$ This issue has been analyzed by Andersen and Bollerslev (1998) who evaluate $\operatorname{GARCH}(1,1)$ forecasts of latent volatility using the sum of high-frequency squared returns as a proxy for ex post daily volatility. Based on a simulation of integrated volatility implied by the $\operatorname{GARCH}(1,1)$ diffusion limit, they find that the sum of high-frequency squared returns is a less noisy measure of latent volatility than is squared daily returns. This superior proxy for ex post volatility facilitates a more accurate assessment of the GARCH forecasts.

A theoretical motivation for using the sum of high-frequency squared returns to compute measures of volatility at lower frequencies dates is provided by Merton (1980). ${ }^{2}$ Andersen, Bollerslev, Diebold, and Labys (1999) extend the theoretical justification for this measure to the class of semimartingales and, using a ten-year sample of five-minute returns for exchange rates, provide stylized facts associated with the distributions of volatility and correlation at daily (and lower) frequencies. They refer to the sum of intraday squared returns as realized volatility.

Rather than using realized volatility to gauge the potential performance of GARCH forecasts (Andersen and Bollerslev (1998)) or characterizing distributions of ex post volatility (Andersen, Bollerslev, Diebold, and Labys (1999)), our paper uses this nonparametric measure to analyze the time series behavior of FX volatility. Following the earlier literature, we use the sum of intraday squared returns (realized volatility) as an observable proxy for daily ex post volatility. However, we explicitly incorporate the fact that, for practical sampling frequencies, realized volatility will not be an error-

\footnotetext{
${ }^{1}$ An alternative proxy for daily ex post volatility that is efficient and easy to calculate is the price range over a day. This has been used by Hsieh (1993) and Alizadeh, Brandt, and Diebold (1999) among others.

${ }^{2}$ Examples of this practice include Poterba and Summers (1986), French, Schwert, and Stambaugh (1987), Schwert (1989), Schwert (1990), Schwert and Seguin (1990), Hsieh (1991), and Taylor and Xu (1997).
} 
free measure of ex post latent volatility. Although very few assumptions are necessary to ensure that the measurement error is an innovation process, a model of latent volatility is required to fully characterize the distribution of that error. Specifying a functional relationship between our direct estimate of volatility and the latent DGP for daily volatility, allows the latter to be parameterized in terms of realized volatility, other variables in the information set, and an error term. In this framework, standard latent volatility models become variants of an ARMAX time series model.

In addition to proposing a structure that links time-series models of volatility to their functional form in term of realized volatility, this paper tests for nonlinear departures from the linear (in parameters) ARMAX representation of realized volatility. To do this we introduce a new model that permits regime switching within an ARMAX model, and does not require simulation methods for estimation. In particular, our semi-Markov ARMAX alternative allows for regime switching in the conditional mean and in the conditional variance of realized volatility. The transition probabilities governing the discrete unobserved state variables and the conditional mean of volatility are both functions of the duration of the state. This framework allows us to investigate the importance of time-varying parameters and timevarying persistence, in contrast to standard volatility models. In addition to capturing large abrupt changes in the level of realized volatility, our structure models time-variation in the conditional variance of volatility.

The importance of nonlinear effects in volatility are gauged by in-sample statistical tests and by out-of-sample forecasts. These analyses show the semi-Markov model to be a good description of FX volatility dynamics. In particular, we find strong statistical evidence of regime changes in both the conditional mean and conditional variance of realized volatility. With respect to shifts in the mean, our results support the usefulness of recent research exploring the combination of volatility clustering models with nonlinearities such as structural changes or regime switching dynamics. ${ }^{3}$ For example, in keeping with the results of Lamoureux and Lastrapes (1990) and Kim and Kon (1999), capturing shifts in the mean of volatility lowers estimates of the persistence of shocks to volatility. However, in addition, we also find evidence of regime switches in the conditional variance of $\mathrm{FX}$ volatility. This new result highlights the issue of time-variation in the volatility of volatility which is important for vega hedging and for pricing derivatives.

Switches between states in our model are associated with discrete changes

\footnotetext{
${ }^{3}$ These approaches include: Markov-switching volatility models such as Turner, Startz, and Nelson (1989), Pagan and Schwert (1990); threshold ARCH models such as Gourieroux and Monfort (1992); and switching ARCH and stochastic volatility models such as Cai (1994), Hamilton and Susmel (1994), Gray (1996), Klaassen (1998) and So, Lam, and Li (1998).
} 
in realized volatility. One of the states captures periods of high volatility in FX rates. Switches from the normal state to that state are characterized by an abrupt increase in the level of realized volatility combined with a large increase in the variance of realized volatility. The estimates indicate that this state is not initially persistent unless the high levels of volatility continue for several periods in which case the state becomes persistent. Thus, extremely high levels of volatility are not expected to occur often, but periodically explosions in volatility may persist for some time. Note that this flexibility of our parameterization, which incorporates time-varying persistence, allows that state to capture observations in the tail of the unconditional distribution of volatility (for example, due to news announcements) as well as more sustained episodes of high volatility.

Our evidence of nonlinearity in realized volatility has several important implications. Firstly, the nonlinear model provides superior out-of-sample forecasts. By identifying periods of high volatility, forecasts during normal periods can be held with more confidence. Secondly, modeling large abrupt changes in volatility will have important effects on derivative security pricing. For example, Jorion (1988) finds evidence of jumps in FX markets and shows that they explain some of the mispricing in currency options. The timevarying variance of volatility found in this paper is important for hedging and for pricing derivatives for which the underlying is a volatility measure, such as a volatility index. We utilize a pseudo trading exercise to show that the volatility forecasts from the nonlinear model dominate those from the linear model when the criterion is profits associated with trading FX straddle contracts.

This paper is organized as follows: Section 2 reviews the theoretical and practical issues involved in measuring daily volatility. Data sources are detailed in Section 3. The form of GARCH and stochastic volatility models in terms of realized volatility is explained in Section 4 as well as the semiMarkov nonlinear model. Details on the model estimates, including out-ofsample evaluation, are found in Section 5. Section 6 provides a discussion of the results and Section 7 concludes.

\section{Volatility Measures}

In this section, we introduce notation for instantaneous and integrated latent volatilities, for daily realized volatilities, and for potential errors associated with using realized volatility to measure integrated latent volatility. In particular, daily realized volatility is defined as the sum of intraday squared returns. The latter are fully observable and provide a nonparametric estimate of latent volatility over the same time interval. We briefly discuss the conditions for realized volatilities to be consistent and unbiased estimates 
of the latent volatility associated with possible data generating processes (DGPs).

\subsection{Constructing Daily Volatility Measures}

We label latent volatility as $\sigma^{2}$ and use $(t)$ to denote instantaneous variables and subscripts to denote discrete quantities. Let $\tilde{\sigma}_{t}^{2}$ be latent volatility for day $t$ which has been aggregated over the interval $(t, t+1)$ where a full 24 hour day is represented by the time interval 1 . To illustrate these concepts consider the following simple diffusion process with no conditional mean dynamics,

$$
d p(t)=\sigma(t) d W(t)
$$

where $p(t)$ is the instantaneous logarithm of price, $d W(t)$ is a standard Brownian process, and $\sigma(t)$ is a stochastic process independent of $d W(t)$. For this diffusion, latent volatility associated with day $t$ is the integral of the instantaneous variances over the day,

$$
\tilde{\sigma}_{t}^{2}=\int_{t}^{t+1} \sigma^{2}(\omega) d \omega
$$

This is an ex post measure of latent volatility associated with day $t$.

Merton (1980) showed that integrated volatility (2.2) can be approximated to an arbitrary precision using the sum of the intraday squared returns. In our case, these nonparametric estimates of $\tilde{\sigma}_{t}^{2}$ are labelled $\hat{\sigma}_{t}^{2}$ and are computed $\mathrm{as}^{4}$

$$
\hat{\sigma}_{t}^{2}=\sum_{j=0}^{\delta-1} r_{t+j / \delta}^{2},
$$

where $r_{t+j / \delta}=p_{t+j / \delta}-p_{t+(j-1) / \delta}$ defines continuously compounded returns, sampled $\delta$ times per day. Note that the subscript $t$ indexes the day while $j$ indexes the time within day $t$ (i.e. $\{(t, j) \mid t=1, \ldots, T ; j=0, \ldots, \delta-1\}$ ). For example, in our empirical application, the interval is 1 day and the price process is sampled every 5 minutes in order to compute 5 -minute returns. This implies that $\delta=288$. Andersen, Bollerslev, Diebold, and Labys (1999) refer to $\hat{\sigma}_{t}^{2}$ as daily realized volatility.

The quadratic variation of the diffusion process implies that Equation (2.3) will provide a consistent estimate of latent volatility over day $t$ since

$$
\operatorname{plim}_{\delta \rightarrow \infty} \sum_{j=0}^{\delta-1} r_{t+j / \delta}^{2}=\tilde{\sigma}_{t}^{2} .
$$

\footnotetext{
${ }^{4}$ Andreou and Ghysels (2000) evaluate the impact of window length, data frequency, weighting scheme, and estimation methods (block versus rolling sample) for the relative efficiency of estimates of integrated volatility associated with diffusions.
} 
As the sampling frequency from a diffusion is increased, the sum of squared returns converges to the integrated volatility over the fixed time interval. Andersen, Bollerslev, Diebold, and Labys (1999) generalized this result to the class of special (finite mean) semimartingales. This class encompasses processes used in standard arbitrage-free asset pricing applications, such as, Ito diffusions, jump processes, and mixed jump diffusions.

This approach could also be applied to the case of a discrete high-frequency price process. For example, consider a discrete-time DGP for intraday FX returns,

$$
r_{t+j / N}=\sigma_{t+j / N} z_{t+j / N}, \quad z_{t+j / N} \sim \operatorname{IID}(0,1)
$$

in which $r_{t+j / N}=p_{t+j / N}-p_{t+(j-1) / N}, p_{t}$ is the log price, and $N$ is the total number of price quotes in a day. ${ }^{5}$ The (2.5) specification encompasses discrete-time stochastic volatility as well as GARCH processes.

\subsection{Measurement Error Issues}

If it were possible to increase the sampling frequency of prices $(\delta \rightarrow \infty)$, realized volatility would provide an error-free measure of latent volatility. However, discrete price quotes and other institutional and behavioral features of the trading process (such as, bid-ask bounce) make sampling at very high frequencies impossible or impractical. In this paper, we explicitly account for various sources of measurement error that might be associated with using realized volatility as a measure for latent volatility over a day.

One source of measurement error could arise from discretization $(\delta$ is finite) since the true stochastic volatility process generates quotes at frequencies higher than our 5-minute sampling frequency. Secondly, the price quotes may be influenced by market microstructure dynamics which can induce autocorrelation in high-frequency FX returns. ${ }^{6}$ To deal with such sources of measurement error, we define $\epsilon_{t}$ as the difference between $\tilde{\sigma}_{t}^{2}$ (the maintained latent volatility for day $t$ ) and its estimate $\hat{\sigma}_{t}^{2}$ (daily realized volatility). That is,

$$
\hat{\sigma}_{t}^{2}=\tilde{\sigma}_{t}^{2}+\epsilon_{t}
$$

Equation (2.6) makes it clear that we are not treating realized volatility as an error-free measure of latent volatility.

As noted above, the nonparametric estimator $\hat{\sigma}_{t}^{2}$, given by (2.3), will provide consistent estimates of latent volatility for a broad class of DGPs.

\footnotetext{
${ }^{5}$ The ex post latent volatility of returns for day $\mathrm{t}$ associated with this discrete-quote DGP is, $\tilde{\sigma}_{t}^{2}=\sum_{j=0}^{N-1} \sigma_{t+j / N}^{2}$, and an estimate of $\tilde{\sigma}_{t}^{2}$ is $(2.3)$ where $\delta=N$.

${ }^{6}$ Bai, Russell, and Tiao (1999) show that autocorrelation and non-normal innovations can have important effects on measurement error and thus on the accuracy of the estimator.
} 
However, the accuracy of daily realized volatilities as measures of ex post daily latent volatilities will depend on the maintained DGP and on the properties of $\epsilon_{t}$. Since the diffusion maintained in (2.1) is driftless, $\hat{\sigma}_{t}^{2}$ will be an unbiased estimator for $\tilde{\sigma}_{t}^{2}$, and the measurement error will be a martingale difference sequence $\left(E_{t-1} \epsilon_{t}=0\right){ }^{7}$ Although unbiasedness will not hold in the presence of a drift in the underlying DGP, $\hat{\sigma}_{t}^{2}$ will still be a consistent estimator of $\tilde{\sigma}_{t}^{2}$.

For example, consider the DGP (2.5) for which $\epsilon_{t}$ takes the form

$$
\epsilon_{t}=\hat{\sigma}_{t}^{2}-\tilde{\sigma}_{t}^{2}=\sum_{j=0}^{N-1} \sigma_{t+j / N}^{2}\left(z_{t+j / N}^{2}-1\right) .
$$

Under the null of that DGP, $z_{t+j / N} \sim \operatorname{IID}(0,1)$ and is independent of $\sigma_{t+j / N}^{2}$. Therefore, although $\epsilon_{t}$ is heteroskedastic, it is mean zero and $\hat{\sigma}_{t}^{2}$ will be an unbiased estimator for $\tilde{\sigma}_{t}^{2}$ for this DGP.

Equation (2.6) links our volatility estimate $\hat{\sigma}_{t}^{2}$ to the contemporaneous measure of daily latent volatility $\tilde{\sigma}_{t}^{2}$. However, these measures of volatility are not always synonymous with conditional variance. One example is when the conditional variance is defined to be measurable with respect to a prior information set. An example of the latter is the popular GARCH specification of conditional variance. To illustrate this case, we define $\tilde{\sigma}_{t \mid t-1}^{2}$ as the GARCH conditional variance which is measurable with respect to information at $t-1$, consisting of past daily returns, so that

$$
\tilde{\sigma}_{t}^{2}=\tilde{\sigma}_{t \mid t-1}^{2}+w_{t}
$$

in which $w_{t}$ captures the difference between conditioning information associated with $\tilde{\sigma}_{t \mid t-1}^{2}$ as opposed to $\tilde{\sigma}_{t}^{2}$. Substituting (2.8) into (2.6) gives us,

$$
\hat{\sigma}_{t}^{2}=\tilde{\sigma}_{t \mid t-1}^{2}+v_{t}+\epsilon_{t}=\tilde{\sigma}_{t \mid t-1}^{2}+\epsilon_{t}^{*}
$$

where $\epsilon_{t}^{*}$ incorporates both contemporaneous measurement error and conditioning information innovations.

\section{Data Sources and Issues}

Ten years of FX prices recorded every 5 minutes were obtained from Olsen and Associates. The data are constructed from logarithmic middle-prices (averages of log bid and ask quotes) for the DEM-USD exchange rate from the interbank FX market for the period Monday, December 1, 1986, 00:00:00

\footnotetext{
${ }^{7}$ See Barndorff-Nielsen and Shephard (2000). Additional assumptions on the underlying DGP may allow one to further characterize the distribution of $\epsilon_{t}$.
} 
GMT to Sunday, December 1, 1996, 00:00:00 GMT. These prices are interpolated to a 5-minute grid using the nearest quotes which bracket the grid point. The dataset also includes a data-hole indicator variable designating whether the quotes used for interpolation are more than 5 minutes away on both sides of the grid point of the constructed quote. If this is the case, the indicator variable takes the value 1 , otherwise it is 0 . Days with runs of such indicators equal to one indicate data gaps due to a problem with the recording or very slow activity in the FX market.

Currencies trade 24 hours per day, 7 days a week. This results in 1,052,064 5-minute prices for the 10-year sample in the Olsen and Associates dataset. Using these prices we computed 1,052,063 continuously compounded 5-minute returns (expressed in USD terms) and matched those returns with time, date, and day-of-the-week and holiday indicator variables.

In order to construct our measure of realized volatility at a daily frequency, we need to define the boundaries of a day. Following Bollerslev and Domowitz (1993), we define day $t$ as the interval from 21:05 GMT the previous day to 21:00 GMT on day $t$. Based on the motivation summarized in Section 2, the estimate for daily realized volatility is computed by summing squares of the currency's 5-minute returns over the day, that is, using (2.3) with $\delta=288$.

Although it is possible to trade currencies at any time, there will clearly be periods such as weekends (covering the period from 21:05:00 GMT Friday to 21:00:00 GMT Sunday) and holidays, during which there will be very low trading activity. Such periods will generate seasonal effects. Following Andersen, Bollerslev, Diebold, and Labys (1999), we eliminated slow trading days (December 24-26,31, January 1-2) associated with fixed holidays, as well as those for the moving holidays Good Friday, Easter Monday, Memorial Day, July Fourth, Labor Day, Thanksgiving and the day after. Secondly, we calculated the sum of the indicator variable for data 'holes' over a day and removed days in which the sum was greater than 144 (more than one half of the day). In addition to weekends and the holidays mentioned above, this resulted in the removal of an extra 18 days, almost all of which had runs greater than 120 for the indicator value of 1. Finally, we eliminated all of December 1986 due to frequent holidays and runs of the indicator variable. In sum, deseasonalizing by removing days with abnormally low trading activity resulted in 709,920 5-minute returns (2465 days) over the period from January 6, 1987 to November $27,1996 .^{8}$

As reported in Table 1, there is autocorrelation in the raw 5-minute returns (up to 4 lags), possibly due to the discrete nature of bid/ask quotes and associated market microstructure dynamics. To conform to the high-

\footnotetext{
${ }^{8}$ Andersen, Bollerslev, Diebold, and Labys (1999) used 2445 days over their sample from December 1, 1986 to December 1, 1996.
} 
frequency DGPs in (2.1) or (2.5), and to ensure that $\epsilon_{t}$ defined in (2.6) is a martingale difference sequence, we filtered the raw 5-minute returns data with an MA(4) including a constant. 9 This filter removes the autocorrelations (see filtered data in Table 1) and potential trends in the data.

Let $\hat{\sigma}_{t, \text { raw }}^{2}$ denote realized volatility when all days are used and $\hat{\sigma}_{t}^{2}$ denote realized volatility for deseasonalized data (abnormal trading days eliminated). Estimates of the autocorrelation, spectrum, and empirical distribution for the two data series $\left(\hat{\sigma}_{t, \text { raw }}^{2}\right.$ and $\left.\hat{\sigma}_{t}^{2}\right)$ of the USD-DEM are shown in Figures 2-4. The spikes in the spectrum plot correspond to the seasonal frequencies of 1 week and a half week.

Figure 1 displays time series plots of $\hat{\sigma}_{t}^{2}$ and daily returns, $r_{t}^{2}$. This figure shows realized volatility to be a less variable series than squared daily returns. Table 2 also shows that daily realized volatility computed from intradaily squared returns is less noisy than traditional proxies for ex post daily volatility. In particular, the range of $\hat{\sigma}_{t}^{2}$ is 5.222 as compared to 12.658 for $r_{t}^{2}$ and the standard deviation of $\hat{\sigma}_{t}^{2}$ is 0.487 as compared to 1.010 for $r_{t}^{2}$.

\section{Time-Series Models of Realized Volatility}

In section 2 we discussed a nonparametric measure of ex post volatility which estimates latent volatility over an interval such as a day. Using (2.6) and (2.9) we show how popular daily volatility models can be represented in terms of observable realized volatility.

\subsection{Linear Time-Series Models}

Given the decomposition of realized volatility into daily latent volatility plus error, as specified in (2.6), one can derive the functional form for the timeseries pattern of realized volatility implied by a particular DGP for latent volatility. For example, consider an autoregressive (AR) discrete-time SV specification for the dynamics of daily latent volatility, ${ }^{10}$ that is,

$$
\tilde{\sigma}_{t}^{2}=\mu+\beta\left(\tilde{\sigma}_{t-1}^{2}-\mu\right)+v_{t}
$$

where $v_{t}$ is stochastic and not measurable with respect to an information set consisting of daily returns.

\footnotetext{
${ }^{9}$ Andersen, Bollerslev, Diebold, and Ebens (2000) also use a linear filter to remove serial correlation in high-frequency equity returns. Some alternative approaches, including an estimator used by French, Schwert, and Stambaugh (1987) that corrects for first-order autocorrelation, are discussed in Bai, Russell, and Tiao (1999).

${ }^{10}$ Meddahi and Renault (2000) provide an AR specification of SV that is closed under temporal aggregation. See also Barndorff-Nielsen and Shephard (1998).
} 
One might be tempted to replace daily latent volatility $\tilde{\sigma}_{t}^{2}$ with its nonparametric estimator $\hat{\sigma}_{t}^{2}$ and fit (4.1) using least squares. However, realized volatility measures latent volatility with error. Ignoring potential measurement error may cause an error-in-variables problem. For this reason, we decompose realized volatility into daily latent volatility plus error, as discussed in section 2 and specified in Equation (2.6). Using (2.6) to replace $\tilde{\sigma}_{t}^{2}$ in (4.1) implies that

$$
\hat{\sigma}_{t}^{2}=\mu+\beta\left(\hat{\sigma}_{t-1}^{2}-\mu\right)-\beta \epsilon_{t-1}+\epsilon_{t}+v_{t} .
$$

That is, the SV specification implies an (approximate) $\operatorname{ARMA}(1,1)$ when expressed in terms of realized volatility $\hat{\sigma}_{t}^{2}$, measurement error, and forecast innovations.

As emphasized by Andersen, Bollerslev, Diebold, and Labys (1999), volatility dynamics may involve auxiliary state variables. In this case, optimal forecasts could utilize available information in addition to past realized volatility. One candidate conditioning variable would be the most recent daily innovation to volatility, $r_{t-1}^{2}$. For example, consider a $\operatorname{GARCH}(1,1)$ function specified as $^{11}$

$$
\tilde{\sigma}_{t \mid t-1}^{2}=\mu+\beta\left(\tilde{\sigma}_{t-1 \mid t-2}^{2}-\mu\right)+\alpha r_{t-1}^{2}
$$

in which the notation $\tilde{\sigma}_{t \mid t-1}^{2}$ is used to emphasize that in the GARCH parameterization the conditional variance is measurable with respect to an information set of past daily returns. In this case, using (2.9), we have

$$
\hat{\sigma}_{t}^{2}=\mu+\beta\left(\hat{\sigma}_{t-1}^{2}-\mu\right)+\alpha r_{t-1}^{2}-\beta \epsilon_{t-1}^{*}+\epsilon_{t}^{*}
$$

which is an $\operatorname{ARMA}(1,1)$ for $\hat{\sigma}_{t}^{2}$, our measure of realized volatility, with an added conditioning variable, $r_{t-1}^{2}$, from the agents' information set of returns. We refer to this time-series specification for daily realized volatility as an $\operatorname{ARMAX}(1,1)$ model.

The ARMAX structure implied by the popular SV and $\operatorname{GARCH}(1,1)$ models of latent volatility provides us with a benchmark to gauge the importance of the proposed nonlinear features discussed in the next section. The simple SV and GARCH(1,1) parameterizations (4.1) and (4.3) have several well-known shortcomings in characterizing time-series properties of volatility. In our context, improvements might alternatively be gained by retaining the linear functions but allowing for more flexible innovation distributions, longer lags in the ARMAX or long memory.

\footnotetext{
${ }^{11}$ Such functions have stochastic volatility diffusion limits. See, for example, Nelson (1990) and Duan (1997). For discrete time DGPs, Drost and Nijman (1993) show that weak-GARCH models are closed under temporal aggregation.
} 


\subsection{A Nonlinear Model}

The SV and GARCH(1,1) specifications are both linear in the parameters conditional on realized volatility and past returns. A vast literature has developed from the ARCH model of Engle (1982). Part of this literature investigates whether nonlinear effects are important in the conditional variance function.

In this section we discuss a nonlinear alternative to the linear models. Our model is a discrete mixture of distributions, which can approximate arbitrary densities (see Gottschling, Haefke, and White (1999)). A discrete mixture of distributions is capable of capturing the skewness and kurtosis that we observe in the distribution of volatility (Table 2). Within this class of models we consider a parsimonious hidden Markov model directed by duration-dependent mixing.

The nonlinear specification applied to realized volatility is a discrete-state semi-Markov ${ }^{12}$ model. In this model the duration of a state can affect the conditional moments as well as the transition matrix. ${ }^{13}$ Our model of realized volatility builds on the results in Maheu and McCurdy (2000b) which investigate a model that captures volatility dynamics exclusively through discrete changes in the level of volatility. ${ }^{14}$ Motivated by these findings and the availability of observable volatility in the form of realized volatility, we consider a combination of smooth persistent changes in volatility through an ARMA specification as well as discrete jumps captured by regime switching. This combination of dynamics provides a flexible model which can capture nonlinear features in the conditional and unconditional distributions of realized volatility. It can also capture non-normal innovation distributions.

Begin by assuming that realized volatility is governed by a discrete mixture of distributions. The discrete mixing variable $S_{t} \in\{1,2\}$ is unobserved and depends only on $S_{t-1}$ and its duration $D_{t-1}$. Duration is defined as the

\footnotetext{
${ }^{12}$ In semi-Markov processes the times at which transitions occur are governed by a separate probability distribution, see Howard (1971). Our duration-dependent Markovswitching specification is a variant of a semi-Markov process for which virtual transitions (a move from a state to itself) and actual transitions (a move from state $\mathrm{i}$ to state $\mathrm{j}$ ) are directed by a duration function. The hazard function defined by the duration parameterization implicitly characterizes the holding time (and waiting time) distributions.

${ }^{13}$ Other Markov-switching applications which built on Hamilton (1989) to address issues of duration include Durland and McCurdy (1994), Lam (1997), Filardo and Gordon (1998), Maheu and McCurdy (2000a) and Maheu and McCurdy (2000b). A Bayesian approach to volatility modeling with duration-dependent mixing is presented in Kim and Nelson (1998).

${ }^{14}$ Maheu and McCurdy (2000b) show that a duration-dependent Markov switching (DDMS) model provides a better description of the dynamics of the conditional and unconditional distribution of FX returns compared to GARCH and Markov switching ARCH models. Their results suggest that discrete changes in volatility are an important ingredient in the time-series dynamics of FX returns.
} 
number of consecutive occurrences of a particular state. We record duration up to and including $\tau$ periods in the past. Define the duration of state $S_{t}$ as

$$
D_{t}=\min \left(D_{t-1} I\left(S_{t}, S_{t-1}\right)+1, \tau\right)
$$

$I\left(S_{t}, S_{t-1}\right)=1$ if $S_{t}=S_{t-1}$ and otherwise 0. Durations above $\tau$ are recorded as having a duration of $\tau .{ }^{15}$ Therefore, if duration happens to be greater than the memory of the process (which would be very unlikely) the transition probabilities or any function of $D_{t}$ would be constant after that point.

The transition probabilities are parameterized using the logistic function so that

$$
\begin{aligned}
P_{i i}\left(D_{t-1}\right) & =P\left(S_{t}=i \mid S_{t-1}=i, D_{t-1}=d_{t-1}\right) \\
& =\frac{\exp \left(\gamma_{1}(i)+\gamma_{2}(i) d_{t-1}\right)}{1+\exp \left(\gamma_{1}(i)+\gamma_{2}(i) d_{t-1}\right)} \quad i=1,2
\end{aligned}
$$

where $\gamma_{1}(1), \gamma_{2}(1)$ and $\gamma_{1}(2), \gamma_{2}(2)$ are parameters associated with states 1 and 2 respectively. $P_{i i}\left(D_{t-1}\right)$ is the conditional probability of staying in state $i$ given that we have been in state $i$ for $d_{t-1}$ periods where $i=1,2$. The probability of switching from state $i$ to state $j$, given that we have been in state $i$ for $d_{t-1}$ periods, is $P_{i j}\left(D_{t-1}\right)=1-P_{i i}\left(D_{t-1}\right), \quad i \neq j, j=1,2$.

The semi-Markov model of realized volatility (SM-ARMAX $(1,1))$ extends the linear ARMAX specification with regime switching in the conditional mean and the conditional variance as,

$$
\begin{aligned}
\hat{\sigma}_{t}^{2} & =\mu\left(S_{t}, D_{t}\right)+\beta\left(\hat{\sigma}_{t-1}^{2}-\mu\left(S_{t-1}, D_{t-1}\right)\right)+\alpha r_{t-1}^{2}+\theta \tilde{\eta}_{t-1}+\eta_{t}\left(S_{t}\right) \\
\mu\left(S_{t}, D_{t}\right) & =\phi\left(S_{t}\right)+\psi\left(S_{t}\right) D_{t} \\
\tilde{\eta}_{t-1} & =\hat{\sigma}_{t-1}^{2}-E_{t-2} \hat{\sigma}_{t-1}^{2} \\
\eta_{t}\left(S_{t}\right) & \sim N\left(0, \lambda^{2}\left(S_{t}\right)\right) .
\end{aligned}
$$

In general, an $\operatorname{ARMA}(1,1)$ with regime switching is intractable due to a state space that increases with the sample size. ${ }^{16}$ Our ARMA model augmented with regime switching is an approximation to a true latent variable regimeswitching ARMA model. The approximation is due to the fact in that $\tilde{\eta}_{t-1}$ is not a function of the unobserved state variables but represents the error observed by the econometrician. ${ }^{17}$ By integrating out the dependence of

\footnotetext{
${ }^{15}$ While it is possible to estimate $\tau$, for example using a grid search, we set $\tau=25$ which is large enough to ensure that all the duration effects have been captured.

${ }^{16}$ Billio, Monfort, and Robert (1999) use Bayesian simulation methods to deal with the exploding state space in switching ARMA models.

${ }^{17}$ The accuracy of the approximation depends on the forecast precision for future states. To illustrate, consider a simple two-state MS model $y_{t}=\mu\left(S_{t}\right)+e_{t}$, and let $p_{1, t-1}$ be the inferred probability of state 1 given time t- 1 information. Then if $S_{t}=1, \tilde{e}_{t}=y_{t}-E_{t-1} y_{t}=$
} 
$\eta_{t-1}$ on $S_{t-1}$ and $D_{t-1}, \tilde{\eta}_{t-1}$ represents an estimate of the true (unobserved) innovation $\eta_{t-1}\left(S_{t-1}\right)$.

The model in (4.7) nests the $\operatorname{ARMAX}(1,1)$, which was motivated by a $\operatorname{GARCH}(1,1)$ formulation of latent volatility, and extends it to allow for state dependent variance and regime switching in the conditional mean of realized volatility. ${ }^{18}$ The conditional mean term $\mu\left(S_{t}, D_{t}\right)$ is a function of $S_{t}$ and its duration $D_{t}$ through the coefficients $\phi\left(S_{t}\right)$, and $\psi\left(S_{t}\right)$ respectively.

The earlier linear $\operatorname{ARMAX}(1,1)$ specification is a parsimonious model that imposes strong assumptions on volatility. For example, the unconditional variance and persistence of volatility levels are both assumed to be constant. Furthermore, that parameterization is not well suited to explaining or predicting discrete jumps in volatility levels. However, the SM-ARMAX $(1,1)$ is a nonlinear extension which allows the levels of volatility to change continuously and discretely over time, provides a flexible structure governing persistence of volatility levels through the transition probabilities and duration dependence, and allows for conditional heteroskedasticity in realized volatility.

To discuss duration effects on realized volatility it is useful to define the hazard function. The hazard function is the conditional probability of a state change given the state has achieved a duration $d$. In terms of the transition probabilities the hazard function is,

$$
P_{i j}\left(D_{t-1}\right)=\frac{1}{1+\exp \left(\gamma_{1}(i)+\gamma_{2}(i) d_{t-1}\right)}, \quad i=1,2
$$

A decreasing hazard function is referred to as negative duration dependence while an increasing hazard function is positive duration dependence. The effect of duration on the hazard function is uniquely summarized by the parameters $\gamma_{2}(i) \quad i=1,2$. In particular, for state $i, \gamma_{2}(i)<0$ implies positive duration dependence, $\gamma_{2}(i)=0$ implies no duration effect and $\gamma_{2}(i)>$ 0 implies negative duration dependence. For example, if state 2 displays negative duration dependence and the FX market persists in state 2, then the probability of staying in state 2 increases.

Hamilton (1989) shows that inference regarding the latent variable $S_{t}$ can be constructed recursively. In a similar fashion, inference regarding both

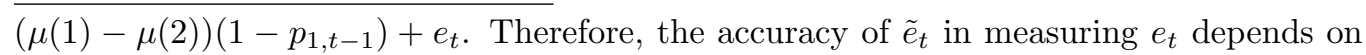
how close the states are $(|\mu(1)-\mu(2)|)$ and/or how close $p_{1, t-1}$ is to 1 . An analogous example applies if $S_{t}=2$. Therefore, models that predict well will provide good estimates of the underlying innovations, that is, $\tilde{e}_{t}$ will be close to $e_{t}$. In our more general case, $\tilde{\eta}_{t-1}$ in (4.7) is an innovation with respect to the information set $\left\{\hat{\sigma}_{t-2}^{2}, \ldots, \hat{\sigma}_{1}^{2}\right\}$ of the econometrician, not with respect to an information set that includes $S_{t-1}$.

${ }^{18}$ This is a slight abuse in terminology since, in order to to nest the earlier linear specifications, the conditional mean of realized volatility is also a function of $\alpha r_{t-1}^{2}$ and the MA(1) term. 
$S_{t}$ and $D_{t}$ can be computed for the semi-Markov model. Define, $f(\cdot \mid \cdot)$ as the conditional density of the normal distribution, and $\Phi_{t}$ as the time $t$ information set available to the econometrician. The filter provides optimal inference for the unobserved variables given time $t$ information. For $S_{t}=1,2$ and $1 \leq D_{t} \leq \tau$ and using $s_{t}$ and $d_{t}$ to denote realized values of $S_{t}$ and $D_{t}$ we have,

$P\left(S_{t}=s_{t}, D_{t}=d_{t} \mid \Phi_{t}\right)=\frac{f\left(y_{t} \mid S_{t}=s_{t}, D_{t}=d_{t}, \Phi_{t-1}\right) P\left(S_{t}=s_{t}, D_{t}=d_{t} \mid \Phi_{t-1}\right)}{P\left(y_{t} \mid \Phi_{t-1}\right)}$

where

$$
\begin{aligned}
P\left(S_{t}=s_{t}, D_{t}=d_{t} \mid \Phi_{t-1}\right) & =\sum_{s_{t-1}, d_{t-1}} P\left(S_{t}=s_{t}, D_{t}=d_{t} \mid S_{t-1}=s_{t-1}, D_{t-1}=d_{t-1}\right) \\
& \times P\left(S_{t-1}=s_{t-1}, D_{t-1}=d_{t-1} \mid \Phi_{t-1}\right)
\end{aligned}
$$

and,

$$
\begin{aligned}
P\left(y_{t} \mid \Phi_{t-1}\right) & =\sum_{s_{t}, s_{t-1}, d_{t-1}} f\left(y_{t} \mid S_{t}=s_{t}, D_{t}=d_{t}, \Phi_{t-1}\right) \\
& \times P\left(S_{t}=s_{t}, D_{t}=d_{t} \mid S_{t-1}=s_{t-1}, D_{t-1}=d_{t-1}\right) \\
& \times P\left(S_{t-1}=s_{t-1}, D_{t-1}=d_{t-1} \mid \Phi_{t-1}\right)
\end{aligned}
$$

The filter plays an important role in forecasts of current as well as future levels of realized volatility. One step ahead forecasts from this model are ${ }^{19}$

$$
\begin{aligned}
& E_{t} \hat{\sigma}_{t+1}^{2}= \sum_{s_{t+1}, s_{t}, d_{t+1}, d_{t}} E_{t}\left[\hat{\sigma}_{t+1}^{2} \mid S_{t+1}=s_{t+1}, S_{t}=s_{t}, D_{t+1}=d_{t+1}, D_{t}=d_{t}\right] \\
& \times \quad P\left(S_{t+1}=s_{t+1}, S_{t}=s_{t}, D_{t+1}=d_{t+1}, D_{t}=d_{t} \mid \Phi_{t}\right)
\end{aligned}
$$

\section{Estimates}

Table 3 presents unrestricted $\operatorname{ARMA}(1,1), \operatorname{ARMAX}(1,1)$ and SM-ARMAX $(1,1)$ estimates for the in-sample observations $1-1800 .^{20}$ Recall that these correspond to SV, GARCH(1,1) and semi-Markov volatility models, respectively,

\footnotetext{
${ }^{19}$ Since the regime switching in the conditional mean affects only the intercept and the memory of duration is truncated at $\tau$, multiperiod forecasts of $\hat{\sigma}_{t+i}^{2}$ are a straightforward generalization of the 1-period forecast. However, an assumed data generating process for the high frequency returns is needed in order to forecast daily squared returns which appear in (4.7). One possibility is to use (2.5) to derive the daily squared return to show $E_{t} r_{t+i}^{2}=E_{t}\left(\sum_{j=0}^{N-1} r_{t+i+j / N}\right)^{2}=E_{t} \tilde{\sigma}_{t+i}^{2}=E_{t} \hat{\sigma}_{t+i}^{2}$, which ensures a closed form solution for multiperiod forecasts of the SM-ARMAX model.

${ }^{20}$ Observations 1801-2465 are saved for out-of-sample evaluation of the models.
} 
expressed in terms of realized volatility. A Ljung-Box (LB) statistic robust to heteroskedasticity is reported for the residuals and a standard LB test for the squared residuals. Results from a heteroskedastic-robust test for neglected nonlinearity $(\mathrm{NL})$ in the residuals from the linear models are also reported in the table. ${ }^{21}$

On the basis of the likelihood, the $\operatorname{ARMAX}(1,1)$ specification for realized volatility suggests a marginal improvement in explaining realized volatility compared to the $\operatorname{ARMA}(1,1)$ specification. In an ideal setting we would like to use our ARMAX estimates to back out parameter estimates of the SV and GARCH models. However, this is not directly possible from Table 3 estimates for two reasons. First, the SV specification of realized volatility in equation 4.2 does not imply an exact ARMA model, and secondly the GARCH parameterization in equation 4.4 puts restrictions on the ARMAX parameters $(\beta=-\theta)$. For example, estimates from an $\operatorname{ARMAX}(1,1)$ with the restriction, $\beta=-\theta$ imposed gave $\hat{\alpha}=.103$ and $\hat{\beta}=.831 .^{22}$ However, the unrestricted ARMAX estimates reported in Table 3 represent a more flexible parameterization of the time series dynamics of realized volatility. We discuss this issue further in section 6 below.

The specification tests for both linear ARMA models reported in Table 3 suggest conditional heteroskedasticity as well as the presence of nonlinear effects in the residuals (NL test). This motivates the SM-ARMAX $(1,1)$ model which is also reported in Table 3. According to the specification tests this model captures the conditional heteroskedasticity and shows a vast improvement in the likelihood. One might expect that this improvement is due to the relaxation of the assumption of a constant conditional variance of volatility imposed in the ARMAX specifications. However, even with no state dependence for the conditional variance of volatility, the loglikelihood is improved from -938.770 to -486.031 . That is, about one half of the increase in loglikelihood for SM-ARMAX relative to ARMAX can be attributed to conditional mean dynamics and the other half to dynamics of the conditional variance of volatility. There are a number of nonlinear dynamics that the SM-ARMAX $(1,1)$ uncovers in realized volatility. These issues are explored further in Section 5.3.

\section{$5.1 \quad$ Forecasts}

Although the nonlinear model of realized volatility dominates the linear alternatives in-sample, these results may not extend out-of-sample. Out-of-sample evaluation through 1-step-ahead forecasts are detailed in Tables 4 and 5. In

\footnotetext{
${ }^{21}$ This is a heteroskedastic robust version of the Tsay (1986) test.

${ }^{22} \mathrm{On}$ the other hand, latent volatility estimates using innovations to daily returns (instead of realized volatility) give $\hat{\alpha}=.0497$ and $\hat{\beta}=.914$.
} 
each case estimates for a particular model are fixed at the reported values in Table 3.

Table 4 displays the estimates and $R^{2}$ from a regression of realized volatility at time $t$ on a constant and a model estimate based on time $t-1$ information. For all models the intercept and slope coefficient are individually insignificant from 0 and 1 respectively (a sufficient condition for unbiased forecasts). However, based on $R^{2}$ statistics, the ARMAX model shows a .03 increase (compared to ARMA) in explanatory power for one-step ahead realized volatility, while the SM-ARMAX $(1,1)$ shows a .042 increase. Squared returns are another proxy, although a noisy one, of latent daily volatility. The $\tilde{R}^{2}$ in Table 4 is the $R^{2}$ from a regression of daily squared returns on a constant and a model forecast of realized volatility, This provides a check on the results that use realized volatility as the forecast target. The apparent reduction in forecasting power as measured by the $\tilde{R}^{2}$ in this regression is consistent with the results in Andersen and Bollerslev (1998).

As a comparison, a $\operatorname{GARCH}(1,1)$ model estimated from daily returns data obtained an out-of-sample $R^{2}=.384$. This represents a .033 decrease in explanatory power compared to the $\operatorname{ARMA}(1,1)$ model applied to realized volatility estimates and a .075 decrease relative to the $\operatorname{SM-ARMAX}(1,1)$ specification of the latter. In other words, using realized volatility estimates results in superior forecasts than those based on latent volatility estimates derived from fitting a GARCH model to returns themselves.

Table 5 displays estimates from the out-of-sample regression of realized volatility on 1-step-ahead forecasts from both the $\operatorname{SM-ARMAX}(1,1)$ and $\operatorname{ARMAX}(1,1)$. These results suggest that the nonlinear model provides a marginal improvement in forecasting power. The heteroskedastic t-statistic on the $\operatorname{SM-ARMAX}(1,1)$ forecast is 2.09 while it is -.03 on the $\operatorname{ARMAX}(1,1)$ forecast.

To further investigate the out-of-sample forecasting power of the ARMAX and SM-ARMAX models we considered the following proportional loss (PL) function,

$$
P L=\frac{1}{T} \sum_{t=1}^{T} \log \left(\frac{\hat{\sigma}_{t}^{2}}{E_{t-1} \hat{\sigma}_{t}^{2}}\right) .
$$

Unlike the $R^{2}$ measure reported above, this loss function weights small and large forecast errors equally. If this measure is positive (negative) it means the forecasting model on average underpredicts (overpredicts) future volatility. The perfect measure for this loss function is 0. As shown in Table 4, the out-of-sample loss for the ARMAX was -.224, and for the SMARMAX -.131. A similar ranking of the models is obtained from PL $=$ $\frac{1}{T} \sum_{t=1}^{T} \log \left(\frac{r_{t}^{2}}{E_{t-1} \hat{\sigma}_{t}^{2}}\right)$ which uses squared returns as the forecast target instead of realized volatility. These results indicate that all models tend to 
overpredict realized volatility (and squared returns), with the linear models doing this to a greater degree. One potential explanation for this difference is that linear ARMA models imply an exponential decay associated with innovations to realized volatility; whereas the nonlinear SM-ARMAX specification has the ability to make immediate abrupt adjustments in volatility as a result of a new innovation.

\subsection{A Profitability Assessment of Variance Forecasts}

To augment the statistical evaluation in the last section, this section follows Engle, Hong, Kane, and Noh (1993) by deriving a profitability measure of the relative ranking of the alternative variance forecasts. In particular, we use ex ante variance forecasts to price European-style put and call options on a spot foreign currency position. These options are priced using the BlackScholes (BS) formula adapted to FX spot market positions (Garman and Kohlhagen (1983)). The options are then combined into a straddle position with one straddle price computed using the ARMAX volatility forecast and an alternative straddle price computed using the the SM-ARMAX volatility model.

A straddle is a natural choice to gauge the relative merits of our volatility models as it is a bet on future volatility. In particular, a long straddle is the simultaneous purchase of a call and a put option on the same currency. We price call and put options which have the same maturity and are both atthe-money (ATM). A short straddle is the simultaneous sale of a call and put option on the same currency. The long straddle will become profitable if the realized volatility increases substantially whereas a short position will be profitable if the realized volatility is lower than the market expected.

The market consists of two investors. One investor is assigned the ARMAX volatility model to generate 1-period out-of-sample volatility forecasts while the other investor uses the SM-ARMAX volatility model for the same purpose. Each investor prices a straddle utilizing their own volatility forecast but the same at-the-money strike prices, foreign and domestic interest rates. A short time-to-expiration (one day) is used to better approximate the constant volatility assumption in the Black-Scholes pricing formula. The straddle is re-priced every day by each investor using updated 1-step ahead volatility forecasts.

The market operates as follows. Each investor prices an ATM straddle on one Deutsche Mark contract which is set at 62,500 Deutsche Marks (as is the case for European FX options traded on the Philadelphia stock market). We assume that the investors are U.S. based. The call $c_{t}$, and put price $p_{t}$, 
which make up a straddle are priced according to the following equations,

$$
\begin{aligned}
c_{t} & =S_{t} e^{-r_{f}(T-t)} N\left(d_{1}\right)-X_{t} e^{-r(T-t)} N\left(d_{2}\right) \\
p_{t} & =X_{t} e^{-r(T-t)} N\left(-d_{2}\right)-S_{t} e^{-r_{f}(T-t)} N\left(-d_{1}\right) \\
d_{1} & =\frac{\log \left(S_{t} / X_{t}\right)+\left(r-r_{f}+\sigma_{t}^{2} / 2\right)(T-t)}{\sigma_{t} \sqrt{T-t}} \\
d_{2} & =d_{1}-\sigma_{t} \sqrt{T-t}
\end{aligned}
$$

where $N(\cdot)$ is the cumulative distribution function for the standard normal distribution, $T-t$ is the annualized time to maturity, $r$ and $r_{f}$, are the annualized domestic and foreign interest rates respectively, and the one period ahead annualized variance forecast from a particular model is substituted for $\sigma_{t}^{2}$.

To make the trading market operational we assign one forecasting model as the investor and another forecasting model as the market maker. The investor initiates trades based on comparing his/her own straddle price to that posted by the market maker. For example, if the investor's straddle price is greater than the market maker's then the investor buys 1 straddle from the market maker, otherwise the investor goes short and sells 1 straddle to the market maker. After next period's spot price is realized payouts are calculated. This is repeated every day for 664 out-of-sample periods.

There are several potential problems in interpreting the results from the option market. First, the assumed pricing formula is misspecified, and therefore profits may be a reflection of superior forecasts and/or pricing model misspecification. In our pseudo option market the investor and market maker both price straddles using the same pricing formula - only volatility forecasts differ. Hence, having the forecast models ARMAX and SM-ARMAX trade against each other should minimize the effects of pricing misspecification and instead reflect the relative merits of the volatility forecasts. ${ }^{23}$

Table 6 shows two particular runs of our pseudo market with $r=.04$ and $r_{f}=.05$. The first run assigns the role of market maker to the SM-ARMAX model and the second reverses roles so that the investor is the SM-ARMAX model. In both cases, the nonlinear (SM-ARMAX) model makes money against the ARMAX model. For example, the number of days with positive returns is almost two to one in favor of the nonlinear model. Average daily net gain for the nonlinear model is $\$ 32.90$ (almost 15 percent of the average price for one straddle contract) while the linear model had an average loss of $\$ 22.20$ per day. The standard errors in Table 6 show the average profit to

\footnotetext{
${ }^{23}$ Note that a priori, there is no reason to think that the ARMAX or SM-ARMAX are systematically profiting from the BS misspecification since the volatility forecasting parameters were estimated using realized volatility data independent of any options data or options pricing formula.
} 
be significantly different than 0 . We also explored several other simulations of this market with similar results. The results of this economic evaluation of the alternative forecasts supports the statistical results presented in the previous section. Using either criteria the nonlinear SM-ARMAX parameterization appears to provide superior variance forecasts.

\subsection{Full-Sample Estimates}

In this section we present and discuss the full-sample estimates of the semiMarkov ARMA model. Estimates for the entire sample are found in Table 7. Based on specification tests we found it necessary to include a second MA term for this sample to eliminate residual serial correlation. Figure 5 displays the hazard function for states 1 and 2, and Figure 6 shows the conditional mean of realized volatility as a function of duration.

The estimates provide evidence of regime switching. The test of no regime switching in the conditional mean of realized volatility $(\phi(1)=\phi(2), \psi(1)=$ $\psi(2)=0$ ) and also the test of no regime switching in the conditional variance of realized volatility $(\lambda(1)=\lambda(2))$ are both strongly rejected. Moreover, duration is important in explaining within state changes in the conditional mean. For instance, the t-statistic on $\psi(2)$ is 3.11 and indicates the conditional mean is increasing with the duration of state 2 (see Figure 6). The duration of a state also significantly affects the transition probabilities of both states through $\gamma_{2}(i), i=1,2$.

State 1 of realized volatility is characterized by normal levels of realized volatility $(\mu(1,1)=.246, \mu(1,25)=.150)$ coupled with a low conditional standard deviation $(\lambda(1)=.119)$. State 2 displays a large and increasing level of realized volatility as a function of duration $(\mu(2,1)=.510, \mu(2,25)=$ $1.854)$, as well as a high conditional standard deviation $(\lambda(2)=.746)$. The unconditional probabilities for states 1 and 2 are .81 and .19 respectively.

The hazard function for both states is shown in Figure 5. Recall that this is the probability of exiting a state as a function of duration. Both states have a declining hazard function indicative of negative duration dependence. This figure suggests that the high variance in state 2 is not initially persistent, and on average results in a switch to the lower variance state. However, if realized volatility persists in state 2 for 3 or more periods then it becomes persistent. Therefore, prolonged episodes of high variance in realized volatility, on average, lead to more of the same.

Finally, Figure 7 shows realized volatility with the in-sample fitted values from the semi-Markov model, while Figure 8 plots the probability of the low volatility state (state 1) based on the full-sample smoother for a particularly volatile period in FX markets. Figure 8 indicates that the nonlinear model accurately identifies the sharp increases in the level and the volatility of 
realized volatility.

\section{Discussion}

The SM-ARMAX model is an example of a doubly stochastic process. In this case the two sources of randomness are $\eta_{t}\left(S_{t}\right)$ conditional on the state, and the latent state itself, $\left(S_{t}, D_{t}\right)$. As such, uncertainty about $\hat{\sigma}_{t}^{2}$ comes from these two sources. Although the largest component of uncertainty comes from the innovation variance, $\lambda^{2}\left(S_{t}\right)$ conditional on $S_{t}=1$ or 2 , regime changes and/or regime uncertainty about the conditional mean $\mu\left(S_{t}, D_{t}\right)$ are also an important component of the conditional variance of realized volatility. These two sources of randomness play an important role in the confidence we attach to future forecasts of realized volatility.

There are important differences between the nonlinear model and the linear ARMA models. Contrary to the evidence from the linear models in Table 3, the semi-Markov model indicates that the standard deviation of the innovations to realized volatility is about .13 most of the time ${ }^{24}$ and not .4 as the $\operatorname{ARMA}(1,1)$ and $\operatorname{ARMAX}(1,1)$ estimates imply. Therefore, based on the semi-Markov model, if we are very certain that next period will be normal (i.e. state 1), then from a forecasting perspective we are much more confident about the behavior of realized volatility next period compared to what the linear models suggest. However, our estimates for the nonlinear model show that $19 \%$ of the time realized volatility undergoes a large increase in its conditional standard deviation to .792. This represents an increase of over $600 \%$ in the standard deviation.

It is natural to interpret state 2 as capturing periods characterized by high volatility of FX rates. Switches between that state and the normal state will involve discrete jumps in volatility. This is an important issue in derivative asset pricing. Empirical evidence suggests that some form of discrete jumps may be necessary to fully describe speculative returns (see Andersen, Benzoni, and Lund (1999)). The usual assumption in continuous time models is that a Poisson process describes the discrete jumps. This implies that jumps are independent and not affected by the most recent information set. However, our results suggest that dependence in the probability of discrete jumps may be an important component of FX volatility dynamics.

Although we have presented out-of-sample forecasts for the various models using a particular sample period we also explored a few other sample periods. In summary, we found that forecasting performance of the linear ARMAX models varied greatly, depending on the proportion of extremely

\footnotetext{
${ }^{24} 81 \%$ of the time realized volatility is in state 1 according to the unconditional probabilities.
} 
high levels of realized volatility in the forecasting sample. However, the semi-Markov model consistently produced good forecast results relative to the linear models for different out-of-sample periods. Nevertheless, for small forecasting samples found at the end of our dataset both the $\operatorname{ARMAX}(1,1)$ and the semi-Markov model had out-of-sample $R^{2}$ in excess of .5.

Although several issues arise when discussing persistence, we can ask how today's volatility affects tomorrow's volatility. As noted above, using realized volatility and unrestricted ARMA or ARMAX parameterizations makes it difficult to compare the coefficient estimates in Table 3 to the SV-motivated approximate ARMA function in Equation 4.2 or the GARCH-motivated restricted ARMAX function in Equation 4.4. However, estimates from an AR$\operatorname{MAX}(1,1)$ with the restriction, $\beta=-\theta$ imposed gave $\hat{\alpha}+\hat{\beta}=.934 .^{25}$ This estimate is relatively close to what we would expect for daily return data. ${ }^{26}$ The unrestricted ARMAX estimates reported in Table 3 represent a more flexible model than the $\operatorname{GARCH}(1,1)$, and therefore $\alpha+\beta$ is not necessarily a meaningful measure of persistence in latent daily volatility.

The results from the semi-Markov model indicate that the linear ARMAX $(1,1)$ in realized volatility neglects several nonlinear features. First, our evidence points to a time-varying intercept parameter. Second, our results suggest that the stochastic process governing the time-varying parameters shows dependence. Finally, we find evidence of conditional heteroskedasticity for realized volatility. This study points to the usefulness of recent research exploring the combination of GARCH or SV models with structural changes or regime switching dynamics.

In this paper we have purposely studied levels of realized volatility to build on the large GARCH (Palm (1996)) and SV (Bates (2000), and Chernov, Gallant, Ghysels, and Tauchen (1999)) literature that investigates the importance of nonlinearities and asymmetries in levels of volatility. However, transformations of realized volatility may be useful. For example, density plots in Andersen, Bollerslev, Diebold, and Labys (1999) show that the unconditional distribution of $\log$ transforms of realized volatility is approximately normal. A starting point for such investigations in our context might be to apply a Box-Cox transformation to our ARMAX specification. In fact, this transformation has been used in the GARCH literature (see Higgins and Bera (1992)). The log transform is a special case of the Box-Cox model and is used in EGARCH and many of the SV models. We did some preliminary analysis using log transforms of realized volatility. In summary our main results do not change. The NL test, reported in Table 3 for the ARMAX parameterizations of volatility levels, also strongly rejects an $\operatorname{ARMAX}(1,1)$

\footnotetext{
${ }^{25}$ Equation 4.3 can be rearranged to give, $\tilde{\sigma}_{t}^{2}=\mu(1-\beta)+(\alpha+\beta) \tilde{\sigma}_{t-1}^{2}+\alpha\left(r_{t-1}^{2}-\tilde{\sigma}_{t-1}^{2}\right)$.

${ }^{26}$ Latent volatility estimates using innovations to daily returns (instead of realized volatility) give $\hat{\alpha}+\hat{\beta}=.964$ for this sample.
} 
model of log volatility. We find evidence of regime switching, and the forecasting ranking of the models is preserved. Obviously the dynamics such as persistence in the transition matrix change considerably. However, the main point is that the nonlinear features we uncover in FX volatility are not

eliminated by the log transformation. Future work will investigate some of these issues.

\section{Conclusion}

This paper uses a nonparametric measure of daily volatility (realized volatility) that allows us to investigate the time-series features of latent volatility and sidestep the choice of the innovation distribution driving returns. It is important to note that we explicitly incorporate the fact that realized volatility will not be an error-free measure of ex post latent volatility. Specifying a functional relationship between our direct estimate of volatility and the latent DGP for daily volatility, allows the latter to be parameterized in terms of realized volatility, other variables in the information set, and an error term. In this framework, standard latent volatility models become variants of an ARMAX time series model. Due to our maintained relationship between realized volatility and latent volatility, any time-series characteristics found using the former will also be true of the latter.

We begin by analyzing an ARMAX model and find evidence of nonlinear structure for which we propose a doubly stochastic process with durationdependent mixing. Our nonlinear model uncovers several important features of FX volatility. For example, we find evidence of time-varying persistence in volatility. We also find that the conditional variance of volatility is time varying. FX returns exhibit normal periods of low and relatively stable volatility and other periods of high and fluctuating volatility. The latter state does not occur often but periodically can persist for a longer period of time. The flexibility of our parameterization, which captures both volatility clustering and time-varying persistence, allows the high volatility state to capture short-lived realizations in the tail of the unconditional distribution of volatility (for example, due to announcements) as well as more sustained periods of high variability in FX returns. These different episodes of volatility embody very different levels of confidence that can be attached to forecasts.

Our evidence of nonlinearity in realized volatility has important implications for empirical finance including the precision of forecasts, hedging and pricing of derivatives. This applies both to the effect of large abrupt changes in the level of volatility on FX options and to the effect of the time-varying variance of volatility for pricing derivatives for which the underlying is a volatility measure such as a volatility index. A simple pseudo-trading exercise in which the volatility forecasts are used to price FX straddles shows 
that the volatility forecasts generated by the nonlinear model dominate those from the linear volatility model. 
Table 1: Autocorrelations of the 5 minute date

\begin{tabular}{cccccc}
\hline & 1 & 2 & 3 & 4 & 5 \\
\hline \multirow{2}{*}{ unfiltered } & -.033 & -.016 & -.024 & -.013 & $-.357 \mathrm{e}-02$ \\
& $(.316 \mathrm{e}-02)$ & $(.250 \mathrm{e}-02)$ & $(.224 \mathrm{e}-02)$ & $(.226 \mathrm{e}-02)$ & $(.223 \mathrm{e}-02)$ \\
\multirow{3}{*}{ filtered } & & & & & \\
& $.373 \mathrm{e}-04$ & $.248 \mathrm{e}-04$ & $-.667 \mathrm{e}-04$ & $-.126 \mathrm{e}-03$ & $-.322 \mathrm{e}-02$ \\
& $(.322 \mathrm{e}-02)$ & $(.254 \mathrm{e}-02)$ & $(.224 \mathrm{e}-02)$ & $(.226 \mathrm{e}-02)$ & $(.224 \mathrm{e}-02)$ \\
\hline
\end{tabular}

This table reports the first 5 autocorrelations of the 5 minute quote data before and after a MA(4) filter was applied. Estimates are from GMM and heteroskedastic and autocorrelation consistent standard errors appear in parenthesis.

Table 2: Descriptive Statistics: raw versus adjusted daily data

\begin{tabular}{lcccc}
\hline & $\hat{\sigma}_{t, \text { raw }}^{2}$ & $\hat{\sigma}_{t}^{2}$ & $r_{t}$ & $r_{t}^{2}$ \\
\hline Mean & .374 & .528 & .009 & .488 \\
Stdev & .464 & .487 & .699 & 1.010 \\
Skewness & 3.520 & 3.721 & .010 & 5.391 \\
Kurtosis & 23.890 & 24.085 & 5.288 & 43.733 \\
Min & .000 & .051 & -3.558 & .000 \\
Max & 5.245 & 5.222 & 3.254 & 12.658 \\
\hline
\end{tabular}


Table 3: Volatility Model Estimates, DEM-USD

\begin{tabular}{|c|c|c|c|c|}
\hline & $\operatorname{ARMA}(1,1)$ & $\operatorname{ARMA}(1,1)-r_{t-1}^{2}$ & \multicolumn{2}{|c|}{ SM-ARMA $(1,1)-r_{t-1}^{2}$} \\
\hline & & & $S_{t}=1$ & $S_{t}=2$ \\
\hline \multirow[b]{2}{*}{$\mu$} & .553 & .400 & & \\
\hline & $(.038)$ & $(.041)$ & & \\
\hline \multirow{2}{*}{$\phi\left(S_{t}\right)$} & & & .299 & .560 \\
\hline & & & $(.036)$ & $(.052)$ \\
\hline \multirow{2}{*}{$\psi\left(S_{t}\right)$} & & & -.004 & .045 \\
\hline & & & $(.002)$ & $(.020)$ \\
\hline \multirow{2}{*}{$\beta$} & .902 & .861 & \multicolumn{2}{|c|}{.757} \\
\hline & $(.021)$ & $(.024)$ & \multicolumn{2}{|c|}{$(.027)$} \\
\hline \multirow{2}{*}{$\alpha$} & & .041 & \multicolumn{2}{|c|}{.058} \\
\hline & & $(.007)$ & \multicolumn{2}{|c|}{$(.007)$} \\
\hline \multirow{2}{*}{$\theta$} & -.615 & -.613 & \multirow{2}{*}{\multicolumn{2}{|c|}{$\begin{array}{l}-.425 \\
(.035)\end{array}$}} \\
\hline & $(.043)$ & $(.042)$ & & \\
\hline \multirow{2}{*}{$\lambda\left(S_{t}\right)$} & .410 & .408 & .132 & .797 \\
\hline & $(.007)$ & $(.007)$ & $(.005)$ & $(.039)$ \\
\hline \multirow{2}{*}{$\gamma_{1}\left(S_{t}\right)$} & & & 1.744 & -.502 \\
\hline & & & $(.178)$ & $(.208)$ \\
\hline \multirow{2}{*}{$\gamma_{2}\left(S_{t}\right)$} & & & .035 & .181 \\
\hline & & & $(.016)$ & $(.053)$ \\
\hline \multirow{2}{*}{$\tilde{Q}(10)$} & 15.131 & 11.251 & \multicolumn{2}{|c|}{14.092} \\
\hline & {$[.127]$} & {$[.338]$} & \multicolumn{2}{|c|}{$[.169]$} \\
\hline \multirow{2}{*}{$Q^{2}(10)$} & 52.772 & 53.916 & \multicolumn{2}{|c|}{6.524} \\
\hline & {$[.000]$} & {$[.000]$} & \multicolumn{2}{|c|}{$[.769]$} \\
\hline \multirow{2}{*}{ NL } & 54.600 & 48.077 & & \\
\hline & {$[.000]$} & {$[.000]$} & & \\
\hline $\lg l$ & -948.282 & -938.770 & \multicolumn{2}{|c|}{10.279} \\
\hline
\end{tabular}

Standard errors appear in parenthesis and p-values in square brackets. The maintained model for the $\operatorname{ARMA}(1,1)$, and $\operatorname{ARMA}(1,1)-r_{t-1}^{2}$ is,

$$
\hat{\sigma}_{t}^{2}=\mu+\beta\left(\hat{\sigma}_{t-1}^{2}-\mu\right)+\alpha r_{t-1}^{2}+\theta \epsilon_{t-1}+\epsilon_{t}, \quad \epsilon_{t} \sim i i d\left(0, \lambda^{2}\right) .
$$

The SM-ARMA $(1,1)-r_{t-1}^{2}$ is,

$$
\begin{aligned}
\hat{\sigma}_{t}^{2} & =\mu\left(S_{t}, D_{t}\right)+\beta\left(\hat{\sigma}_{t-1}^{2}-\mu\left(S_{t-1}, D_{t-1}\right)\right)+\alpha r_{t-1}^{2}+\theta \tilde{\eta}_{t-1}+\eta_{t}\left(S_{t}\right) \\
\mu\left(S_{t}, D_{t}\right) & =\phi\left(S_{t}\right)+\psi\left(S_{t}\right) D_{t} \\
\tilde{\eta}_{t-1} & =\hat{\sigma}_{t-1}^{2}-E_{t-2} \hat{\sigma}_{t-1}^{2}, \quad \eta\left(S_{t}\right) \sim N\left(0, \lambda^{2}\left(S_{t}\right)\right)
\end{aligned}
$$

with state transition probabilities from equation (4.6) $\tilde{Q}(10)$, is a heteroskedastic robust version of the Ljung-Box statistic for serial correlation in the residuals with 10 lags, while $Q^{2}(10)$ is the standard Ljung-Box statistic on the squared residuals. NL is a test for neglected nonlinearity in the residuals based on a heteroskedastic robust Wald test of $\pi_{2}=0$, in

$$
\begin{aligned}
& \hat{\epsilon}_{t}=z_{t} \pi_{1}+w_{t} \pi_{2}+\text { error } \\
& z_{t}=\left[1, \hat{\epsilon}_{t-1}, \ldots, \hat{\epsilon}_{t-p}\right], \quad w_{t}=\left[\hat{\epsilon}_{t-1}^{2}, \hat{\epsilon}_{t-1} \hat{\epsilon}_{t-2}, \ldots, \hat{\epsilon}_{t-p}^{2}\right]
\end{aligned}
$$

which is a $.5 p(p+1)$ degree of freedom test.24he NL test sets $p=4$. Data observations are from 1 to 1800. 
Table 4: Out-of-Sample Forecast Results, DEM-USD

\begin{tabular}{cccc}
\hline & ARMA(1,1) & ARMA(1,1)-r $r_{t-1}^{2}$ & SM-ARMA(1,1)-r $r_{t-1}^{2}$ \\
\hline \multirow{2}{*}{$c_{0}$} & -.069 & -.074 & -.050 \\
& $(.046)$ & $(.044)$ & $(.042)$ \\
$c_{1}$ & 1.094 & 1.112 & 1.156 \\
& $(.110)$ & $(.107)$ & $(.109)$ \\
$R^{2}$ & .417 & & .459 \\
$\mathrm{PL}$ & -.237 & -.224 & -.131 \\
\hline \hline & & & \\
$\tilde{R}^{2}$ & .039 & .039 & .041 \\
$\tilde{\mathrm{PL}}$ & -1.828 & -1.816 & -1.722 \\
\hline
\end{tabular}

The test regression is

$$
\hat{\sigma}_{t}^{2}=c_{0}+c_{1} E_{t-1} \hat{\sigma}_{t}^{2}+\text { error }
$$

where $E_{t-1} \hat{\sigma}_{t}^{2}$ is the particular model based 1 step-ahead forecast. Model estimates are obtained using observation 1-1800, and thereafter fixed. Out-of-sample observations are from 1801-2465. Heteroskedastic consistent standard errors appear in parenthesis. The proportional loss function is

$$
P L=\frac{1}{T} \sum_{t=1}^{T} \log \left(\frac{\hat{\sigma}_{t}^{2}}{E_{t-1} \hat{\sigma}_{t}^{2}}\right)
$$

$\tilde{R}^{2}$ is the $R^{2}$ from the test regression using daily squared returns,

$$
r_{t}^{2}=c_{0}+c_{1} E_{t-1} \hat{\sigma}_{t}^{2}+\text { error. }
$$

and

$$
\tilde{\mathrm{PL}}=\frac{1}{T} \sum_{t=1}^{T} \log \left(\frac{r_{t}^{2}}{E_{t-1} \hat{\sigma}_{t}^{2}}\right)
$$


Table 5: Forecast Comparisons, DEM-USD

\begin{tabular}{lllll}
\hline$c_{0}$ & $c_{1}$ & $c_{2}$ & $R^{2}$
\end{tabular}

\begin{tabular}{rrrr}
-.049 & 1.172 & -.016 & .460 \\
The test regression is & $(.561)$ & $(.522)$ & \\
\hline
\end{tabular}

$$
\hat{\sigma}_{t}^{2}=c_{0}+c_{1} E_{t-1}^{1} \hat{\sigma}_{t}^{2}+c_{2} E_{t-1}^{2} \hat{\sigma}_{t}^{2}+\text { error }
$$

where $E_{t-1}^{1} \hat{\sigma}_{t}^{2}$ is the 1 step-ahead forecast from the SM$\operatorname{ARMA}(1,1)-r_{t-1}^{2}$ and $E_{t-1}^{2} \hat{\sigma}_{t}^{2}$ is the 1 step-ahead forecast from the $\operatorname{ARMA}(1,1)-r_{t-1}^{2}$. Out-of-sample observations are from 18012465. Heteroskedastic consistent standard errors appear in parenthesis.

Table 6: Relative Profitability of Variance Forecasts

\begin{tabular}{|c|c|c|c|}
\hline Investor & $\begin{array}{l}\text { Market } \\
\text { Maker }\end{array}$ & $\begin{array}{c}\text { Investor's Average } \\
\text { Daily Gain }\end{array}$ & $\begin{array}{c}\text { Percentage of Days } \\
+ \text { Gain }\end{array}$ \\
\hline 1 ARMAX & SM-ARMAX & $\begin{array}{r}-22.200 \\
(7.106)\end{array}$ & $35 \%$ \\
\hline 2 SM-ARMAX & ARMAX & $\begin{array}{c}32.902 \\
(7.403)\end{array}$ & $67 \%$ \\
\hline
\end{tabular}

This table includes 2 runs of the pseudo straddle market. The investor is the model listed in the left hand column and initiates trades against the market maker. The domestic and foreign interest rates are fixed at $r=.04$ and $r_{f}=$ .05 , respectively. Heteroskedasticity and autocorrelation consistent standard errors appear in parentheses. The total out-of-sample trading days is 664 . 
Table 7: Full-Sample SM-ARMA(1,2)- $r_{t-1}^{2}$ Estimates, DEM-USD

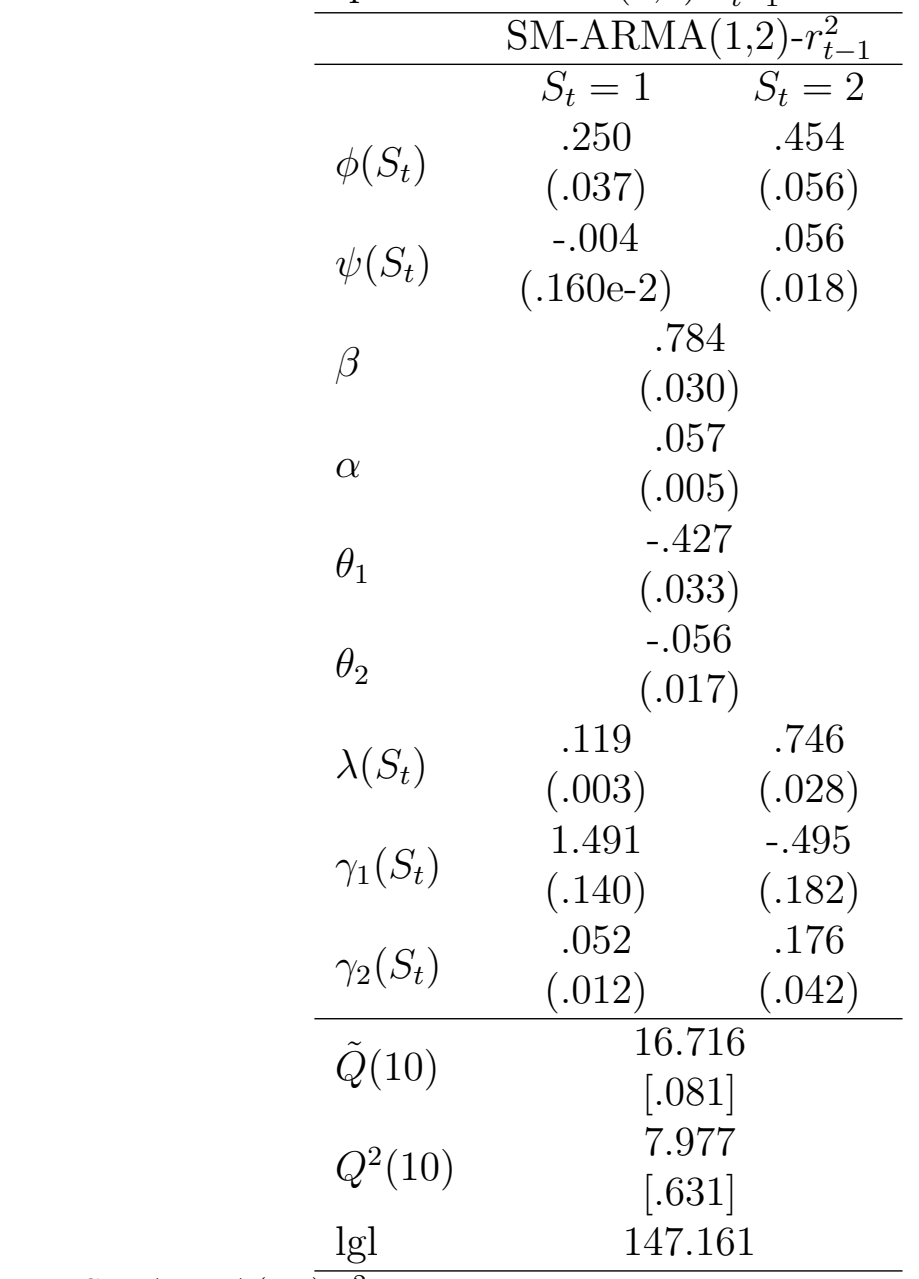

The SM-ARMA $(1,2)-r_{t-1}^{2}$ is,

$$
\begin{aligned}
\hat{\sigma}_{t}^{2} & =\mu\left(S_{t}, D_{t}\right)+\beta\left(\hat{\sigma}_{t-1}^{2}-\mu\left(S_{t-1}, D_{t-1}\right)\right)+\alpha r_{t-1}^{2}+\theta_{1} \tilde{\eta}_{t-1}+\theta_{2} \tilde{\eta}_{t-2}+\eta_{t}\left(S_{t}\right) \\
\mu\left(S_{t}, D_{t}\right) & =\phi\left(S_{t}\right)+\psi\left(S_{t}\right) D_{t} \\
\tilde{\eta}_{t-1} & =\hat{\sigma}_{t-1}^{2}-E_{t-2} \hat{\sigma}_{t-1}^{2} \\
\eta\left(S_{t}\right) & \sim N\left(0, \lambda^{2}\left(S_{t}\right)\right)
\end{aligned}
$$

with state transition probabilities from equation (4.6) $\tilde{Q}(10)$, is a heteroskedastic robust version of the Ljung-Box statistic for serial correlation in the residuals with 10 lags, while $Q^{2}(10)$ is the standard Ljung-Box statistic on the squared residuals. 
Figure 1: Squared Returns and Realized Volatility, DEM-USD
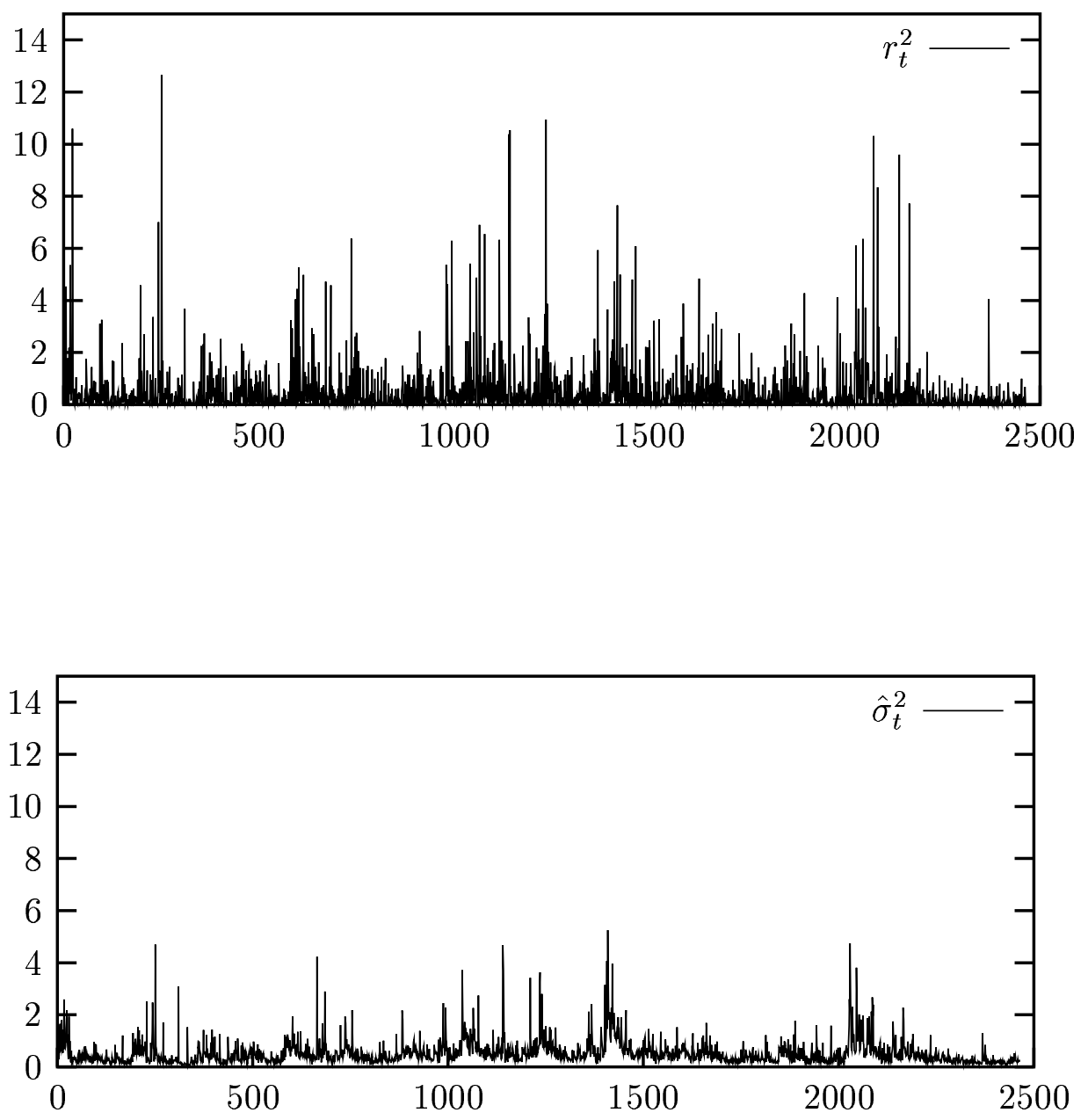
Figure 2: DEM-USD Sample Autocorrelations

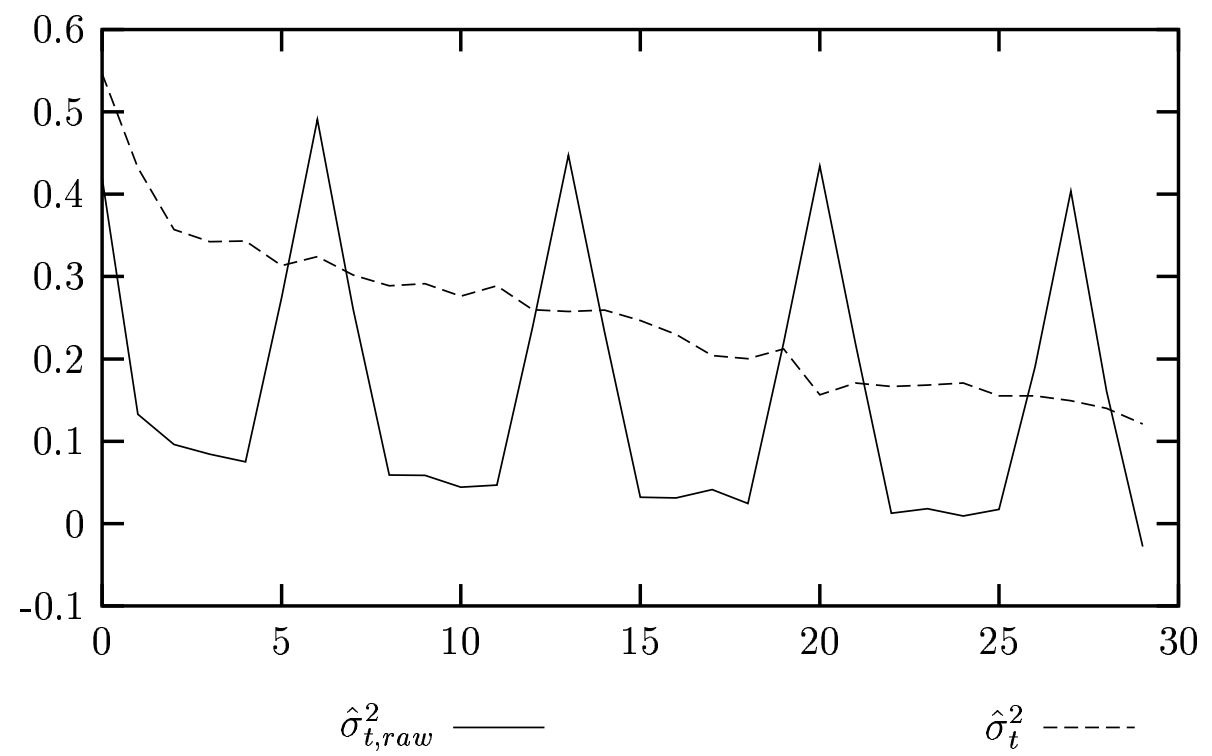

Figure 3: DEM-USD Spectrum Estimates

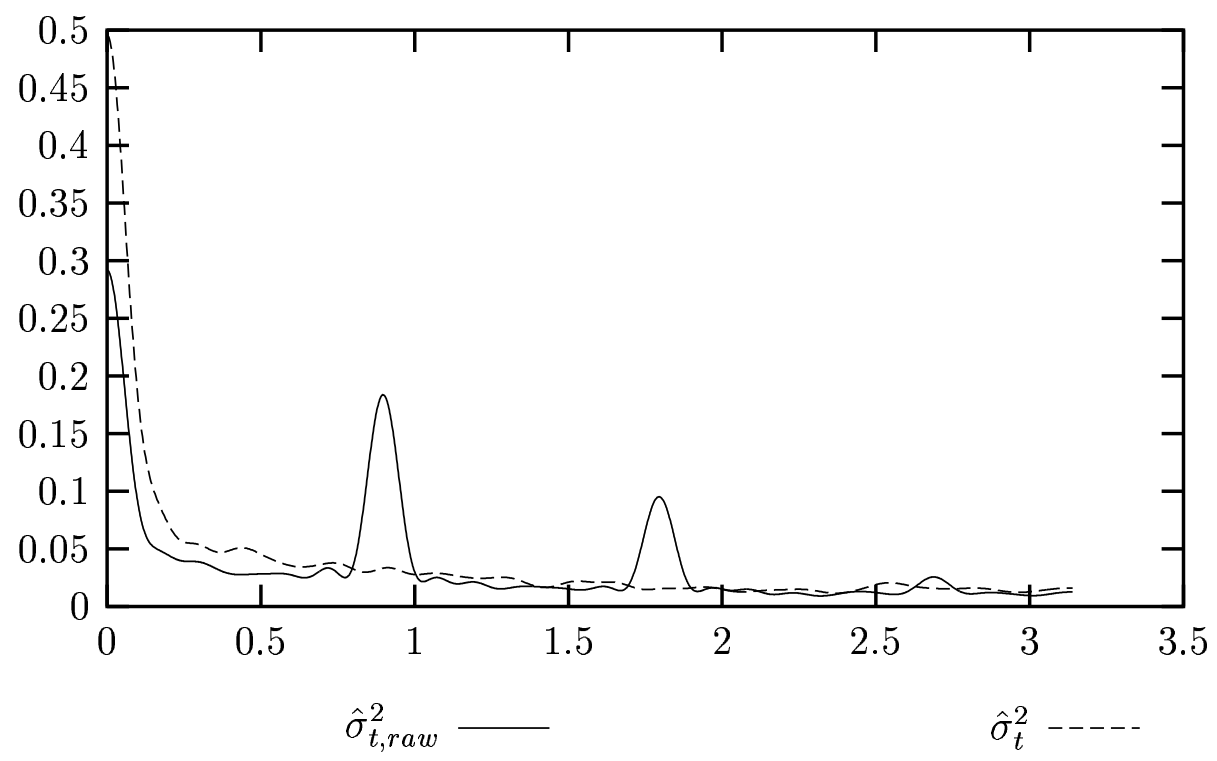


Figure 4: DEM-USD Empirical Distribution Function

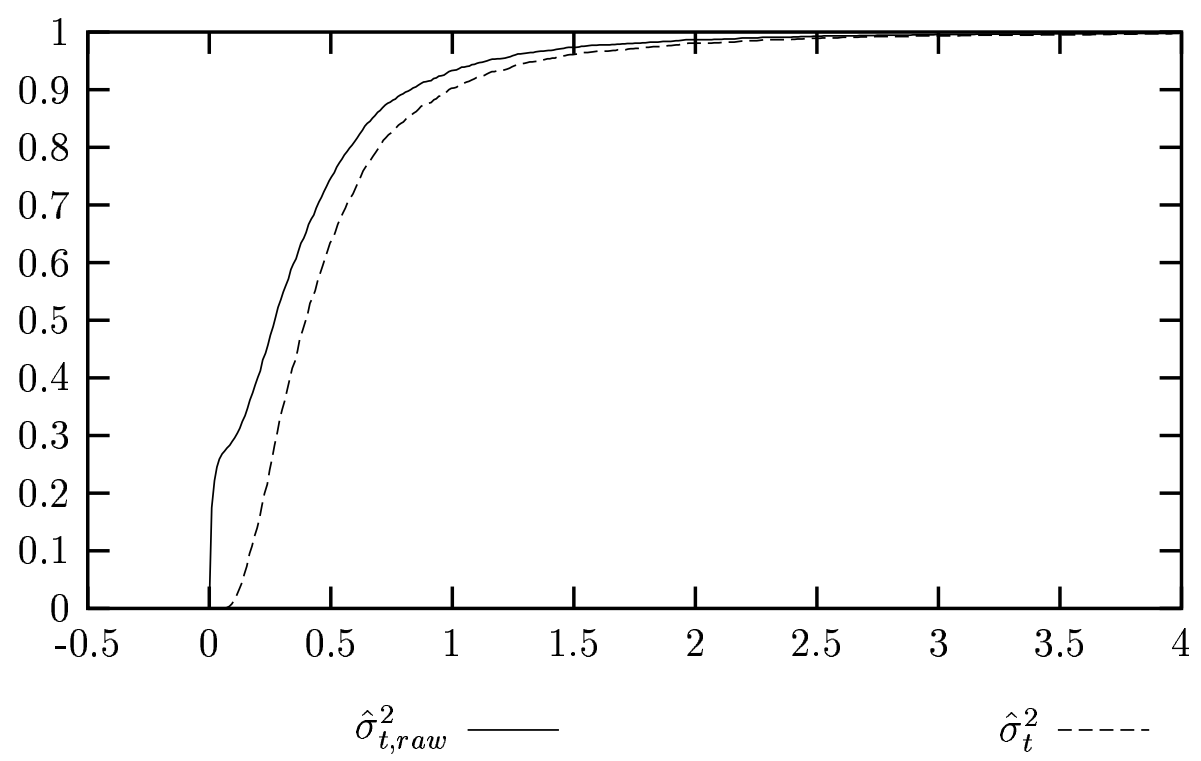

Figure 5: Hazard Function for SM-ARMA $(1,2)-r_{t-1}^{2}$

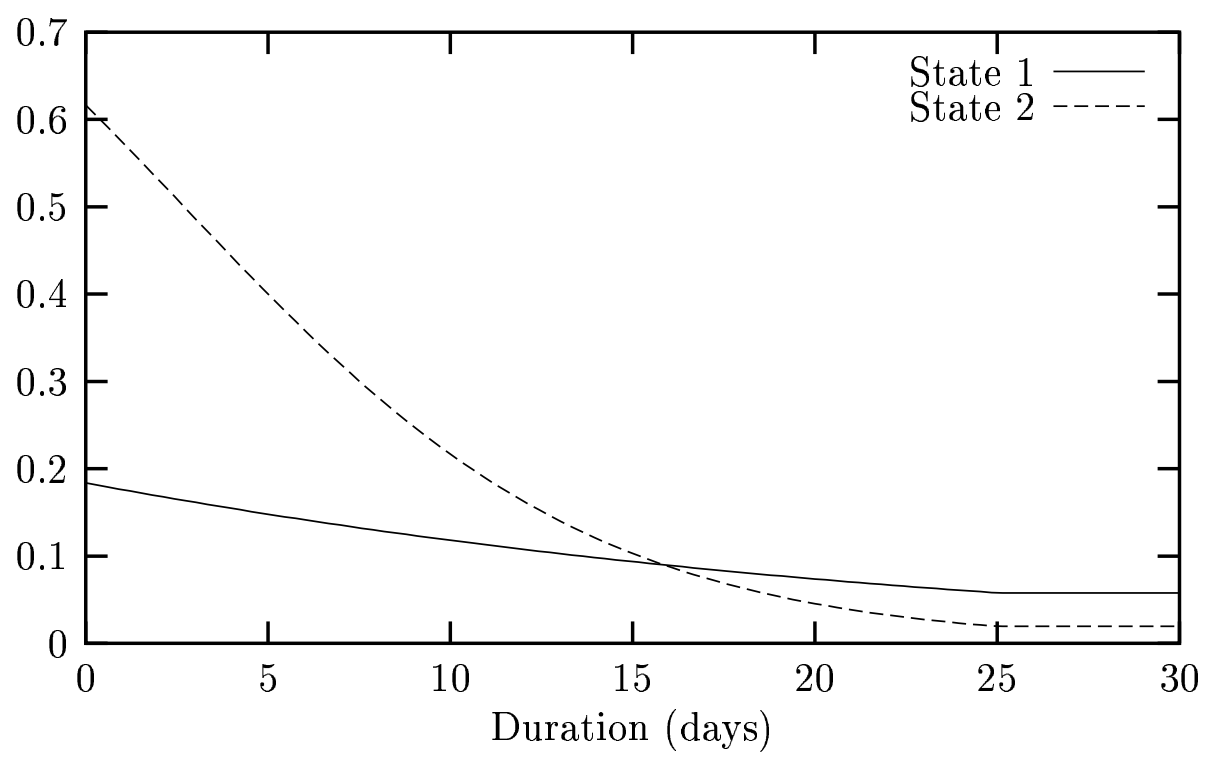


Figure 6: Conditional Mean as a Function of Duration $\phi\left(S_{t}\right)+\psi\left(S_{t}\right) D_{t}$

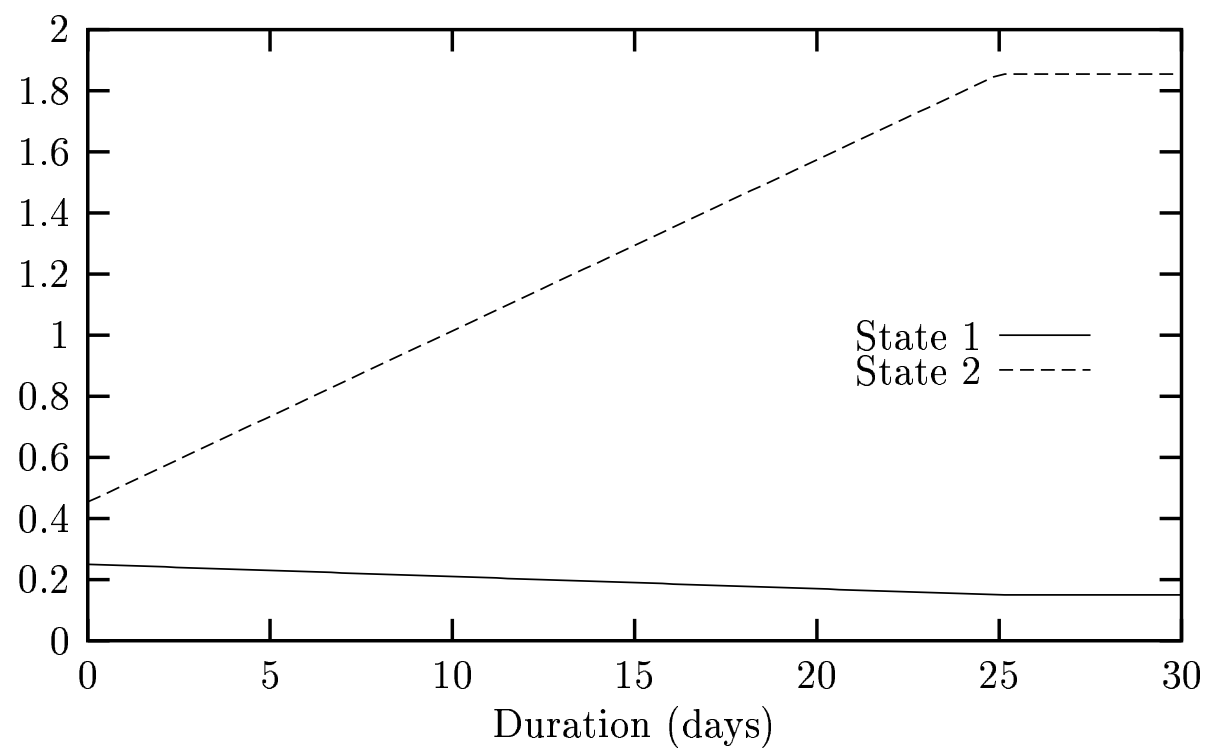




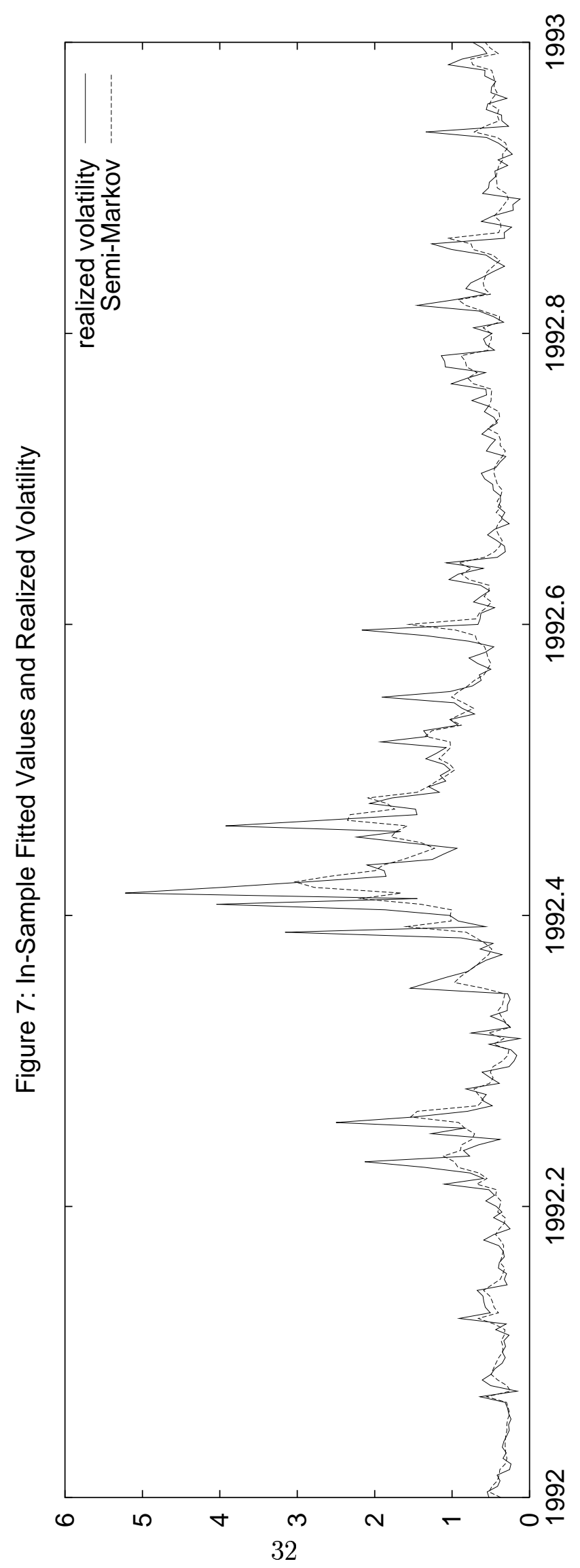




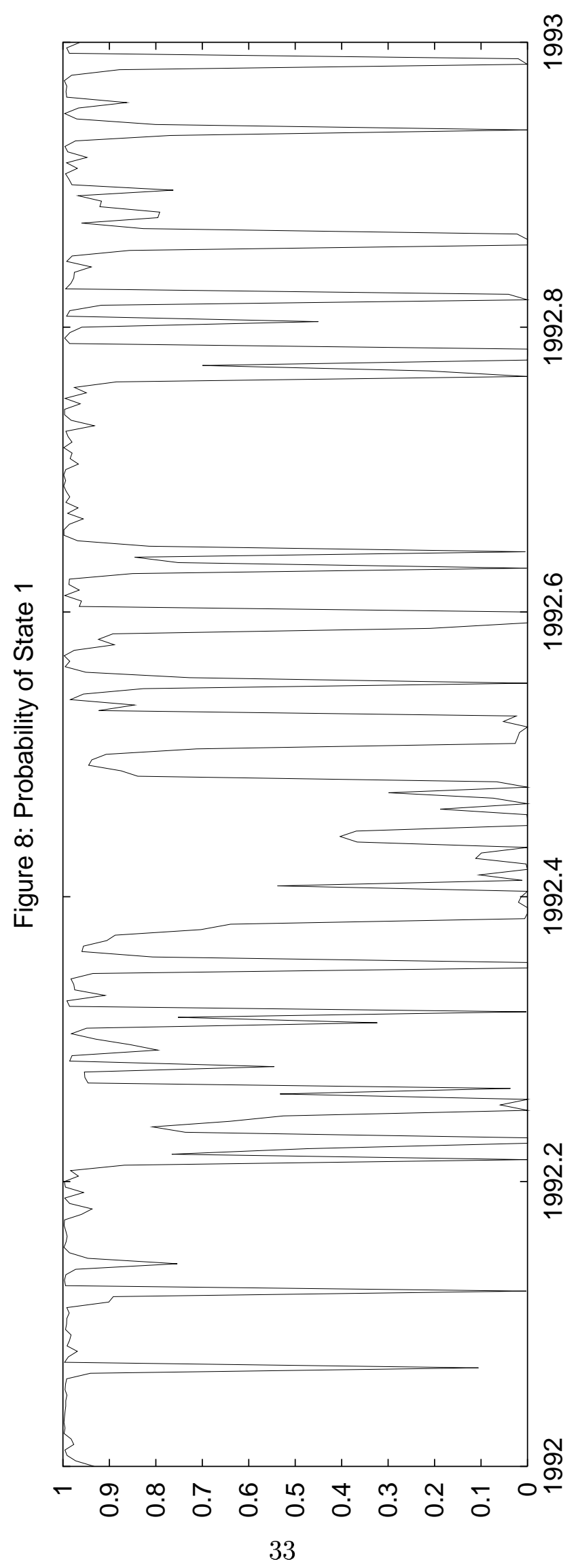




\section{References}

Alizadeh, S., M. W. Brandt, and F. X. Diebold (1999): "RangeBased Estimation of Stochastic Volatility Models," Stern School, NYU.

Andersen, T. G., L. Benzoni, and J. Lund (1999): "Estimating JumpDiffusions for Equity Returns," Kellogg Graduate School of Management, Northwestern University.

Andersen, T. G., And T. Bollerslev (1998): "Answering the Skeptics: Yes, Standard Volatility Models DO Provide Accurate Forecasts," International Economic Review, 39(4), 885-905.

Andersen, T. G., T. Bollerslev, F. X. Diebold, and H. Ebens (2000): "The Distribution of Stock Return Volatility," Economics Department, Duke University.

Andersen, T. G., T. Bollerslev, F. X. Diebold, and P. Labys (1999): "The Distribution of Exchange Rate Volatility," Stern School of Business.

Andreou, E., And E. Ghysels (2000): "Rolling-sample Volatility Estimators: Some New Theoretical, Simulation and Empirical Results," University of North Carolina, Chapel Hill.

Bai, X., J. R. Russell, and G. C. Tiao (1999): "Beyond Merton's Utopia: effects of non-normality and dependence on the precision of variance estimates using high-frequency financial data," Graduate School of Business, University of Chicago.

Barndorff-Nielsen, O., And N. Shephard (1998): "Aggregation and Model Construction for Volatility Models," Nuffield College, Oxford.

Barndorff-Nielsen, O. E., And N. Shephard (2000): "Econometric Analysis of Realised Volatility and its use in Estimating Levy Based NonGaussian OU Type Stochastic Volatility Models," Nuffield College, Oxford.

Bates, D. S. (2000): "Post-'87 Crash Fears in the S\&P 500 Futures Option Market," Journal of Econometrics, 94, 181-238.

Billio, M., A. Monfort, And C. Robert (1999): "Bayesian Estimation of Switching ARMA Models," Journal of Econometrics, 93(2), 229-255.

Bollerslev, T., and I. Domowitz (1993): "Trading Patterns and Prices in the Interbank Foreign Exchange Market," Journal of Finance, 48, 14211443. 
CAI, J. (1994): "A Markov Model of Switching-Regime ARCH," Journal of Business 83 Economic Statistics, 12(3), 309-316.

Chernov, M., A. R. Gallant, E. Ghysels, and G. Tauchen (1999): "A new class of stochastic volatility models with jumps: theory and estimation," Working Paper, CIRANO.

Drost, F., and T. Nijman (1993): "Temporal Aggregation of GARCH Processes," Econometrica, 61, 909-927.

DuAn, J.-C. (1997): "Augmented GARCH(p,q) Process and its Diffusion Limit," Journal of Econometrics, 79, 97-127.

Durland, J. M., and T. H. MCCurdy (1994): "Duration-Dependent Transitions in a Markov Model of U.S. GNP Growth," Journal of Business E Economic Statistics, 12(3), 279-288.

Engle, R. F. (1982): "Autoregressive Conditional Heteroskedasticity with Estimates of the UK inflation," Econometrica, 50, 987-1008.

Engle, R. F., C. Hong, A. Kane, and J. Noh (1993): Advances in Futures and Options Research vol. 6, chap. Arbitrage Valuation of Variance Forecasts with Simulated Options, pp. 393-415. JAI Press.

Filardo, A. J., and S. F. Gordon (1998): "Business Cycle Durations," Journal of Econometrics, 85, 99-123.

French, K. R., G. W. Schwert, and R. F. Stambaugh (1987): "Expected Stock Returns and Volatility," Journal of Financial Economics, 19, $3-29$.

Garman, M., and S. Kohlhagen (1983): "Foreign Currency Option Values," Journal of International Money and Finance, 2, 231-237.

Gottschling, A., C. Haefre, and H. White (1999): "Closed Form Integration of Artificial Neural Networks With Some Applications to Finance," Dept of Economics, University of California, San Diego.

Gourieroux, C., And A. Monfort (1992): "Qualitative Threshold ARCH Models," Journal of Econometrics, 52, 159-200.

Gray, S. F. (1996): "Modeling the Conditional Distribution of Interest Rates as a Regime-Switching Process," Journal of Financial Economics, $42,27-62$. 
Hamilton, J. D. (1989): "A New Approach to the Economic Analysis of Non-stationary Time Series and the Business Cycle," Econometrica, 57, $357-384$.

Hamilton, J. D., And R. Susmel (1994): "Autoregressive Conditional Heteroskedasticity and Changes in Regime," Journal of Econometrics, 64, 307-333.

Higgins, M. L., And A. K. Bera (1992): "A Class of Nonlinear ARCH Models," International Economic Review, 33, 137-158.

Howard, R. A. (1971): Semi-Markov and Decision Processes, vol. II of Dynamic Probabilistic Systems. John Wiley \& Sons.

Hsien, D. (1991): "Chaos and Nonlinear Dynamics: Applications to Financial Markets," Journal of Finance, 46, 1839-1877.

Hsien, D. A. (1993): "Implications of Nonlinear Dynamics for Financial Risk Management," Journal of Financial and Quantitave Analysis, 28(1), 41-64.

Jorion, P. (1988): "On Jump Processes in the Foreign Exchange and Stock Markets," Review of Financial Studies, 1(4), 427-445.

Kim, C. J., and C. R. Nelson (1998): "Business Cycle Turning Points, a New Coincident Index, and Tests of Duration Dependence Based on a Dynamic Factor Model with Regime Switching," Review of Economics and Statistics, 80(2), 188-201.

Kim, D., And S. Kon (1999): "Structural change and time dependence in models of stock returns," Journal of Empirical Finance, 6, 283-308.

KlaAssen, F. (1998): "Improving GARCH Volatility Forecasts," Tilburg University.

LAm, P. (1997): “A Markov Switching Model of GNP Growth with Duration Dependence," Federal Reserve Bank of Minneapolis, Discussion Paper 124.

Lamoureux, G. C., and W. D. Lastrapes (1990): "Persistence in Variance, Structural Change, and the GARCH Model," Journal of Business $\&$ Economic Statistics, 8, 225-234.

Maheu, J. M., And T. H. MCCurdy (2000a): "Identifying Bull and Bear Markets in Stock Returns," Journal of Business \& Economic Statistics, 18(1), 100-112. 
(2000b): "Volatility Dynamics under Duration-Dependent Mixing," Journal of Empirical Finance, 7(3-4), 345-372.

Meddahi, N., and E. Renault (2000): "Temporal Aggregation of Volatility Models," University of Montreal.

Merton, R. C. (1980): "On Estimating the Expected Return on the Market: An Exploratory Investigation," Journal of Financial Economics, 8, 323-361.

Nelson, D. B. (1990): "ARCH Models as Diffusion Approximations," Journal of Econometrics, 45, 7-39.

Pagan, A., and G. W. Schwert (1990): "Alternative Models for Conditional Stock Volatility," Journal of Econometrics, 45(1-2), 267-290.

PALM, F. C. (1996): GARCH Models of Volatility chap. 7, Handbook of Statistics vol. 14. Elsevier Science.

Poterba, J., And L. Summers (1986): "The persistence of volatility and stock market fluctuations," American Economic Review, 76, 1142-1151.

Schwert, G. (1989): "Why Does Stock Market Volatility Change Over Time?," Journal of Finance, 44, 1115-1154.

Schwert, G. W. (1990): "Stock Market Volatility," Financial Analysts Journal, 46, 23-34.

Schwert, G. W., And P. J. Seguin (1990): "Heteroskedasticity in Stock Returns," Journal of Finance, 45, 1129-1155.

So, M. K., K. LAm, and W. Li (1998): "A Stochastic Volatility Model with Markov Switching," Journal of Business 8 Economic Statistics, 16, 244-253.

TAYlor, S., AND X. XU (1997): "The Incremental Information in One Million Foreign Exchange Quotations," Journal of Empirical Finance, 4, $317-340$.

Tsay, R. S. (1986): "Nonlinearity Tests for Time Series," Biometrika, 73(2), 461-66.

Turner, C., R. Startz, and C. Nelson (1989): "A Markov Model of Heteroskedasticity, Risk, and Learning in the Stock Market," Journal of Financial Economics, 25, 3-22. 


\section{Liste des publications au CIRANO*}

Série Scientifique / Scientific Series (ISSN 1198-8177)

2001s-41 Job Satisfaction and Quits: Theory and Evidence from the German

Socioeconomic Panel / Louis Lévy-Garboua, Claude Montmarquette et Véronique Simonnet

2001s-40 Logique et tests d'hypothèse : réflexions sur les problèmes mal posés en économétrie / Jean-Marie Dufour

2001s-39 Managing IT Outsourcing Risk: Lessons Learned / Benoit A. Aubert, Suzanne Rivard et Michel Patry

2001s-38 Organizational Design of R\&D Activities / Stefan Ambec et Michel Poitevin

2001s-37 Environmental Policy, Public Interest and Political Market / Georges A. Tanguay, Paul Lanoie et Jérôme Moreau

2001s-36 Wealth Distribution, Entrepreneurship and Intertemporal Trade / Sanjay Banerji et Ngo Van Long

2001s-35 Comparaison des politiques de rémunération en fonction des stratégies organisationnelles / Michel Tremblay et Denis Chênevert

2001s-34 Déterminants et efficacité des stratégies de rémunération : Une étude internationale des entreprises à forte intensité technologique / Michel Tremblay, Denis Chênevert et Bruno Sire

2001s-33 La multiplicité des ancres de carrière chez les ingénieurs québécois: impacts sur les cheminements et le succès de carrière / Yvon Martineau, Thierry Wils et Michel Tremblay

2001s-32 The Impact of Interface Quality on Trust in Web Retailers / Marie-Christine Roy, Olivier Dewit et Benoit A. Aubert

2001s-31 R\&D and Patents: Which Way Does the Causality Run? / Hans van Ophem, Erik Brouwer, Alfred Kleinknecht and Pierre Mohnen

2001s-30 Contracting under Ex Post Moral Hazard and Non-Commitment / M. Martin Boyer

2001 s-29 Project Financing when the Principal Cannot Commit / M. Martin Boyer

2001s-28 Complementarities in Innovation Policy / Pierre Mohnen et Lars-Hendrick Röller

2001s-27 Bankruptcy Cost, Financial Structure and Technological Flexibility Choices / Marcel Boyer, Armel Jacques et Michel Moreaux

2001s-26 Inflation as a Strategic Response / M. Martin Boyer et Pierre Thomas Léger

2001s-25 Simulation-Based Finite-Sample Tests for Heteroskedasticity and ARCH Effects / Jean-Marie Dufour, Lynda Khalaf, Jean-Thomas Bernard et Ian Genest

2001s-24 The Role of Organizational Commitment and Citizenship Behaviors in Understanding Relations between Human Resources Practices and Turnover Intentions of IT Personnel / Guy Paré, Michel Tremblay et Patrick Lalonde

* Consultez la liste complète des publications du CIRANO et les publications elles-mêmes sur notre site Internet : 